\title{
CD36/Fatty Acid Translocase in Rats: Distribution, Isolation from Hepatocytes, and Comparison with the Scavenger Receptor SR-B1
}

\author{
Xingqi Zhang, Rebecca L. Fitzsimmons, Leslie G. Cleland, Peter L. Ey, \\ Andrew C. W. Zannettino, Elizabeth-Anne Farmer, Paul Sincock, and \\ Graham Mayrhofer
}

The Arthritis Research Laboratory (XZ, RLF, LGC, E-AF, GM), Hanson Centre for Cancer Research, and The Department of Molecular Biosciences (XZ, RLF, PLE, E-AF, GM), University of Adelaide, and The Rheumatology Unit (LGC), Royal Adelaide Hospital, and The Division of Haematology (ACWZ, PS), Institute for Medical and Veterinary Science, Adelaide, South Australia, Australia

SUMMARY: The new mAb UA009 recognizes an antigen expressed by microvascular endothelium, by lymphatic endothelium, and by some epithelia in a number of organs, including the small intestine, lactating mammary gland, kidney, lung, sebaceous glands, and circumvallate papillae of the tongue. This antigen is also expressed abundantly in the splenic red pulp and marginal zone and by monocytes, macrophages, and erythrocytes (but not by platelets). Among tissues that store or metabolize fatty acids, the antigen is expressed by adipocytes, cardiomyocytes, and red skeletal muscle. Importantly, it is expressed by steroidogenic cells in the adrenal gland, testis, and ovary, whereas in the liver it is expressed by hepatocytes in a pattern that is dependent on gender and genetic background. mAb UA009 immunoprecipitated a mol wt 85-kDa surface protein from detergent extracts of hepatocytes from Dark Agouti female rats. The N-terminal amino acid sequence of this protein was identical to fatty acid translocase (FAT), the rat cluster of differentiation 36 (CD36) ortholog. The mAb also reacted with COS-7 cells transfected with cDNA encoding FAT. cDNAs encoding a CD36/FAT-like polypeptide were prepared from both liver and heart RNA by RT-PCR. The nucleotide sequences obtained from these cDNAs (Dark Agouti rats) revealed identity and 99\% similarity, respectively, with the published sequences of Cd36/Fat in rats of the Wistar and Sprague-Dawley strains. The absence of the UA009 antigen in CD36/FAT-deficient SHR/N rats confirmed the identity of the UA009 antigen and CD36/FAT. We suggest that CD36/FAT might function in the liver as a sex-regulated accessory molecule, either in reverse cholesterol transport and/or in fatty acid uptake. (Lab Invest 2003, 83:317-332).

$C$ luster of differentiation 36 (CD36) is a glycoprotein that was identified first on human platelets (Okumura and Jamieson, 1976), where it is also known as GPIV or GPIIIb (McGregor et al, 1989; Tandon et al, 1989). The coding sequences of CD36 homologs have been obtained from cloned murine (Endemann et al, 1993) and bovine (Berglund et al, 1996) cDNAs. On platelets, CD36 functions as a receptor for thrombospondin and collagen (Febbraio et al, 2001; McGregor et al, 1989). The molecule is now known to be expressed by a variety of cells and tissues, including vascular endothelium, heart muscle, adipocytes, epithelium of lactating mammary gland, enterocytes of the small intestine, lung alveolar epithelium, cells of

\section{DOI: 10.1097/01.LAB.0000059923.67198.BA}

Received April 30, 2002.

X.Z. is the recipient of an Australian Development Cooperation Scholarship, and R.L.F. is the recipient of a Dawes Scholarship from the Royal Adelaide Hospital Research Committee.

Address reprint requests to: Dr. G. Mayrhofer, Department of Molecular Biosciences, University of Adelaide, South Australia 5005, Australia. E-mail: graham.mayrhofer@adelaide.edu.au the monocyte-macrophage lineage, erythrocyte precursors, and erythrocytes (Abbadia et al, 1997; Edelman et al, 1986; Febbraio et al, 2001; Greenwalt and Mather, 1985; Greenwalt et al, 1990; Knowles et al, 1984; Van Schravendijk et al, 1992). CD36 is a class B scavenger receptor (Febbraio et al, 2001) that binds oxidized low-density lipoproteins (Endemann et al, 1993), anionic phospholipids (Rigotti et al, 1995), and phospholipids on the surfaces of apoptotic cells (Puente Navazo et al, 1996; Sambrano and Steinberg, 1995).

The rat ortholog of CD36 was discovered initially as a fatty acid translocase (FAT). It exhibits $76 \%$ amino acid identity with human CD36 (Abumrad et al, 1993; Harmon et al, 1991; Ibrahimi et al, 1996). Transcripts from this gene (Cd36/Fat) have been identified by Northern analysis in adipocytes, heart muscle, skeletal muscle, intestine, and spleen (Abumrad et al, 1993; van Nieuwenhoven et al, 1995) but, significantly, not in liver. More recently, Fukuwatari et al (1997) amplified a product from cDNA prepared from rat (Wistar strain) circumvallate papillus mRNA using oligonucleotides complementary with sequences in the gene encoding FAT; the nucleotide sequence of this fragment (Fat $c p$ ) 
was similar to the corresponding segment of the Fat gene. Transcripts of Cd36/Fat have also been identified in rat type II pneumocytes (Guthmann et al, 1999).

Another member of the CD36 gene family, scavenger receptor $\mathrm{BI}(\mathrm{SR}-\mathrm{BI})$, has been identified recently in hamsters (Acton et al, 1994), mice (Acton et al, 1996), humans (Calvo and Vega, 1993; Cao et al, 1997; Murao et al, 1997), and rats (Johnson et al, 1998; Landschulz et al, 1996). The SR-BI molecule shares approximately $30 \%$ amino acid identity with CD36. It also shares with CD36 specific binding of modified low-density lipoproteins and anionic phospholipids (Acton et al, 1994; Calvo et al, 1997; Rigotti et al, 1995). In addition, SR-BI and CD36 can bind native high-density lipoproteins (HDL), although CD36 is less effective in mediating cholesteryl ester uptake (Calvo et al, 1998; Connelly et al, 1999; Gu et al, 1998). SR-BI is expressed at high levels by steroidogenic tissues and the liver, in which it seems to have important functions in selective uptake of cholesterol from HDL and in mediating reverse cholesterol transport (Krieger, 1998). A possible contribution from CD36 to reverse cholesterol transport is suggested by the observation that plasma cholesterol is elevated in CD36 gene knockout mice (Febbraio et al, 1999).

CD36 may, therefore, be more important in reverse cholesterol transport than could be expected from the reportedly low expression of CD36/FAT mRNA in rat liver (Abumrad et al, 1993; Pelsers et al, 1999; van Nieuwenhoven et al, 1995) or the comparatively low efficiency of CD36 in transport of cholesteryl ester from HDL (Calvo et al, 1998; Connelly et al, 1999; Gu et al, 1998). In this context, it is noteworthy that although human hepatocytes have been shown to express CD36 (Maeno et al, 1994), there have been no extended immunohistochemical studies on the distribution of CD36/FAT in the rat, despite the importance of this species as a subject for the study of fatty acid and cholesterol metabolism. The only study on CD36/ FAT protein used ELISA to detect the polypeptide in tissue lysates from cardiac and skeletal muscle (Pelsers et al, 1999). There is, therefore, little precise information about which cells express the molecule in most tissues. In part, this is because mAbs specific for rat CD36/FAT have not been available.

We have produced an mAb (UA009) that recognizes an antigen with a tissue distribution similar to CD36. This report describes the detailed cellular distribution of the antigen detected by mAb UA009 (the UA009 antigen [UA009 Ag]) in rat tissues. Although this antigen has some differences in distribution from CD36 in humans and from Cd36/Fat transcripts in rats, there is little doubt from our molecular studies, genetic comparisons, and detailed immunohistochemical studies that we have identified the UA009 Ag correctly. There are important parallels between the expression of CD36/FAT and SR-BI in both the liver and steroidogenic tissues, raising the need for a reassessment of whether CD36/FAT has a role in reverse cholesterol transport and/or transport of fatty acids by these tissues.

\section{Results}

\section{Expression of the UAOOg Ag by Endothelium}

The UA009 Ag was expressed by vascular endothelium in all tissues except the brain and normal endometrium (for negative control, see Fig. 7D). Endothelium of veins and venules expressed the antigen strongly, and it was also expressed strongly by capillaries (Fig. 1, A and B). Endothelium of high endothelial venules (HEV) in the outer paracortex of lymph nodes was unstained, except for surrounding vascular pericytes (Fig. 1C). However, the endothelium expressed UA009 Ag as the HEV approached the corticomedullary border. In contrast, endothelium of HEV in Peyer's patches was stained strongly by mAb UA009 (Fig. 2E). Staining of endothelium in small arteries by $\mathrm{mAb}$ UA009 was variable (Fig. 1B), whereas larger arteries (Fig. 1B), the aorta, and the vena cava were not stained (data not shown). Finally, mAb UA009 also stained lymphatic endothelium (Fig. 1D).

\section{Distribution of the UAOO9 Ag in Lymphoid and Hematopoietic Tissues}

A population of large cells expressing UA009 Ag was prominent in the medulla of the lymph nodes (Fig. 2A). Similar cells in serial sections were stained by mAb WT.5 (anti-rat Mac-1) and they appear, therefore, to be macrophages (not shown). Clusters of myeloid cells were stained by mAb UA009 in cross-sections of

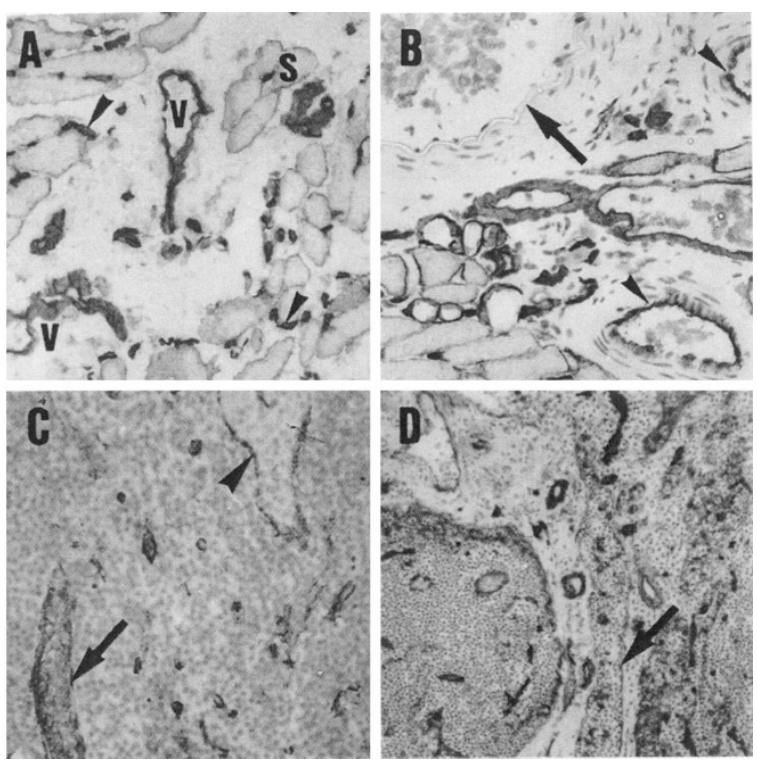

Figure 1.

Expression of the UA009 antigen (UA009 Ag) by vascular and lymphatic endothelia, detected by the indirect immunoperoxidase technique. A, Crosssection of tongue shows staining of capillaries (arrowheads), venule ( $v$ ), and the sarcolemma of red skeletal muscle $(s)$. B, Endothelium in small arteries (arrowheads) in the tongue show patchy staining, whereas endothelium in a larger artery (arrow) is unstained. Artery contains stained red blood cells. C, High endothelial venules (HEV) in the paracortex of a lymph node. One that is more superficial has unstained endothelium and stained pericytes (arrowhead), whereas the HEV nearer the medulla has stained endothelium (arrow). $D$, Endothelium of the efferent lymphatic in a lymph node (arrow) is stained by mAb UA009. Original magnification: $D, \times 41$; A to $C, \times 82$. 

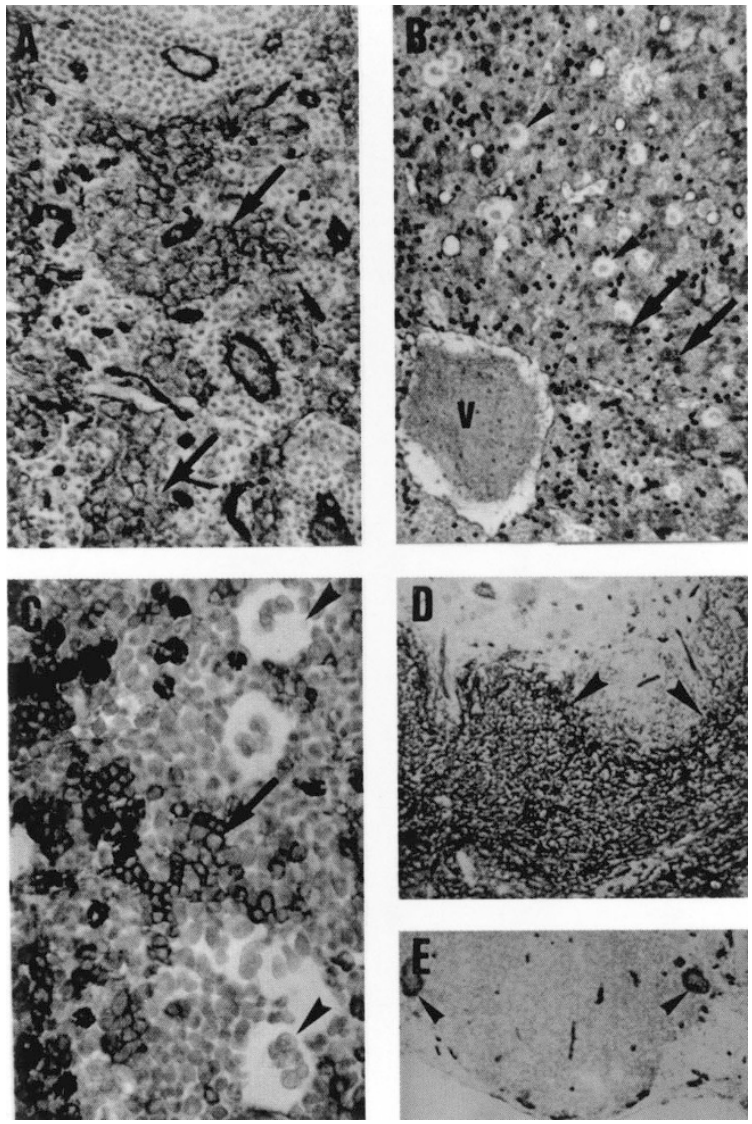

Figure 2.

Expression of the UA009 Ag in lymphoid and hematopoietic tissues, shown by the indirect immunoperoxidase technique. A, Corticomedullary region of a lymph node, showing large stained cells (macrophages) in the medulla arranged in cords and clusters (arrows). B, Cross-section of the tibia, showing marrow and the central vein $(v)$. Staining of endogenous peroxidase in eosinophils appears black. Megakaryocytes (arrowheads) are unstained, whereas clusters of nucleated cells are stained (arrows). C, Megakaryocytes in bone marrow are unstained (arrowheads). Clusters of stained cells of variable size may be erythroid (arrow). D, In spleen, the marginal sinus is stained (arrowheads). Lymphocytes (above) are unstained, but the adjacent marginal zone and red pulp (lower right) are stained densely. E, Lymphocytes in a Peyer's patch follicle are unstained, but HEV (arrowheads) in the interfollicular areas are stained densely. Original magnification: $B, D$, and $E, \times 41 ; A, \times 82$; C, $\times 165$.

tibial bone marrow, but megakaryocytes were unstained (Fig. 2, B and C). There was extensive expression of the UA009 Ag by endothelium of the marginal sinuses and by reticular elements of the marginal zone and the red pulp of the spleen (Fig. 2D). However, lymphocytes in the white pulp of the spleen (Fig. 2D), the lymph nodes (Figs. 1C and 2A), and Peyer's patches (Fig. 2, E and D) were not stained.

Consistent with the lack of the UA009 Ag on megakaryocytes, the antigen was not detected by flow cytometry on blood platelets, whether they were labeled with mAb UA009 when freshly isolated (Fig. $3 A$ ), after activation with thrombin, or after fixation and permeabilization with $0.1 \%$ Saponin (not shown). The antigen was present on approximately $80 \%$ of erythrocytes (Fig. 3B), $90 \%$ of peritoneal macrophages (Fig. $3 \mathrm{C}), 44 \%$ of blood monocytes, and $70 \%$ of macro-
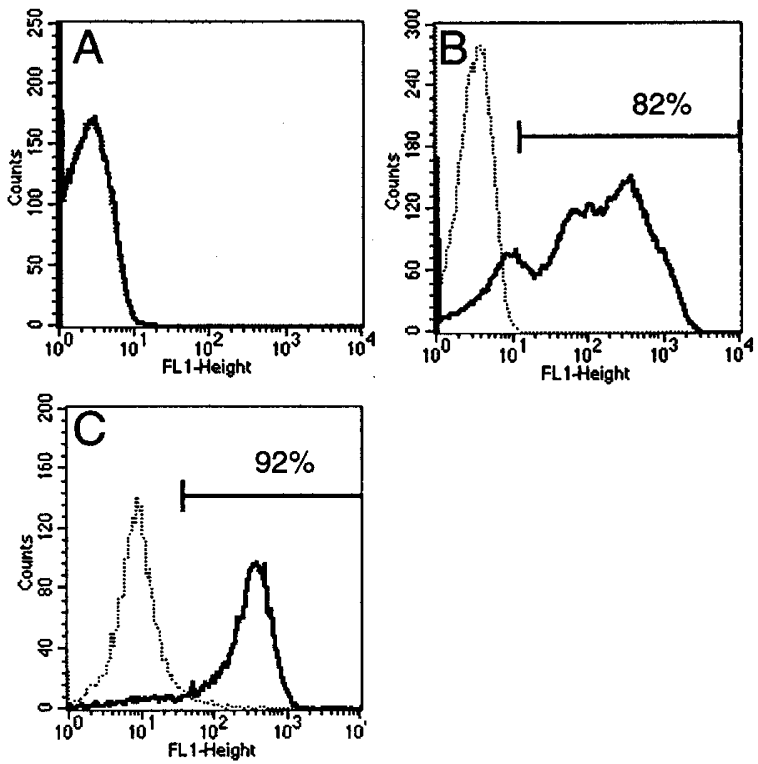

Figure 3.

Flow cytometric analysis of binding by mAb UA009, assessed by indirect immunofluorescence and plotted as histograms of cell number (count) within each bracket of fluorescence intensity (FL1-Height). In each panel, the dotted line shows fluorescence of cells labeled with isotype control $\mathrm{mAb} 1 \mathrm{~B} 5$, and the solid line shows fluorescence of cells labeled with mAb UA009. The percentage of specifically labeled cells is shown above the horizontal bar. A, Freshly prepared platelets. Note that the labeling by mAbs $1 B 5$ and UA009 is identical. B, Freshly prepared red blood cells. C, Freshly prepared peritoneal macrophages.

phages recovered by bronchoalveolar lavage (not shown).

\section{Distribution of the UAOOg Ag in Muscle Tissues}

Cardiac muscle was stained strongly by mAb UA009 (Fig. 4A). To distinguish between the sarcolemma and adjacent vascular endothelium, we examined isolated cardiac myocytes. The surface membranes of the isolated cells were stained strongly by mAb UA009 (Fig. 4B). The antigen was also detected on the sarcolemma of striated muscle fibers in the tongue (Fig. 1A) and in scattered groups in the sternomastoid muscle (Fig. 4C). In typical red muscles such as the diaphragm (Fig. 4D) and the soleus (Fig. 4E), essentially all fibers expressed the UA009 Ag. In contrast, the antigen was not detected on the sarcolemma of white fibers in the gastrocnemius muscle (Fig. 4F).

\section{Expression of the UA009 Ag by Epithelia}

The UA009 Ag was expressed on the brush borders of mature enterocytes in the small intestine (Fig. 5A), by pulmonary alveolar epithelium (not shown), and by ciliated epithelium in both the respiratory tract (Fig. 5B) and the oviducts (not shown). At both sites, the antigen seems to be associated with the lumenal surfaces, including the membranes of the cilia. In glandular tissues, the UA009 Ag was expressed by the lipid-secreting apocrine cells of lactating mammary glands (Fig. 5C) and sebaceous glands (Fig. 5D), but it was not expressed by nonlactating mammary gland 

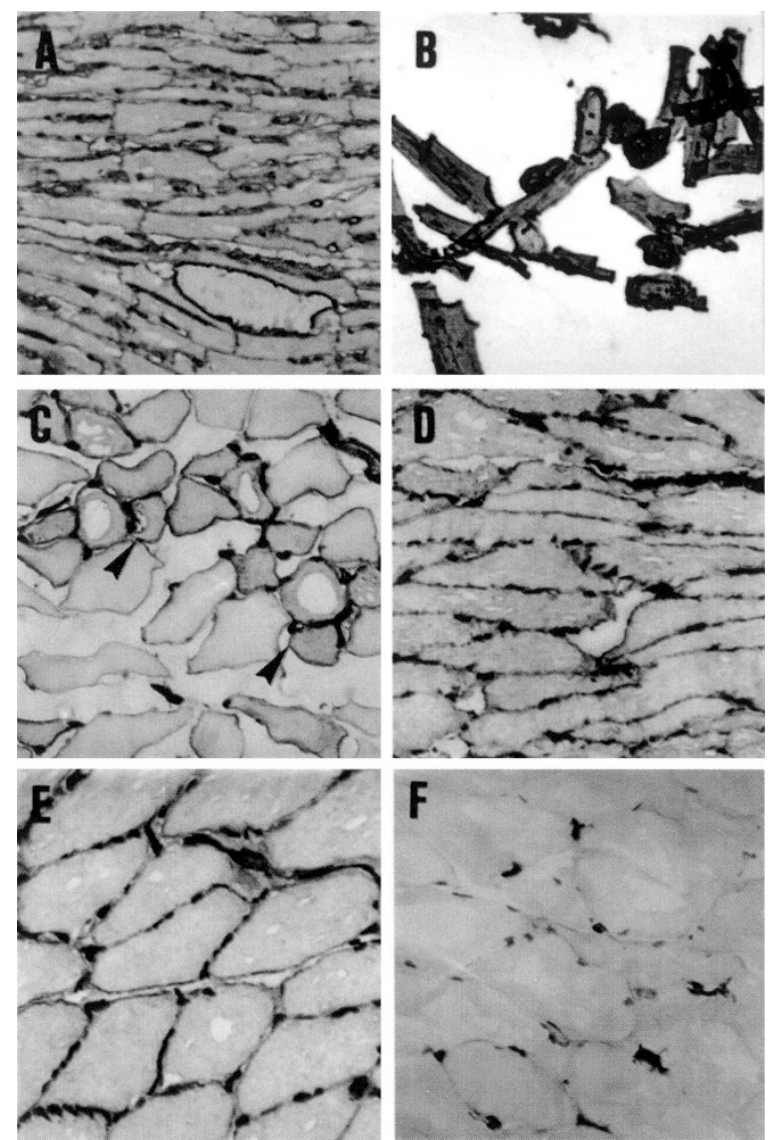

Figure 4.

Detection of cluster of differentiation 36/fatty acid translocase (CD36/FAT) in muscle tissues, using the indirect immunoperoxidase technique. A, Staining of the sarcolemma and intercalated plates in cardiac muscle. B, Stained isolated cardiomocytes. C, Staining of a cluster of red muscle fibers (arrowheads) in the sternomastoid muscle. D, Red muscle fibers in the diaphragm. E, Red muscle fibers in the soleus muscle. $F$, White muscle fibers in the gastrocnemius muscle. Original magnification: $A, \times 41$; $B$ to $F, \times 82$.

epithelium (Fig. 6A). The antigen was expressed with a basal polarity by epithelial cells of the renal convoluted tubules (Fig. 5E), and it was detected on cells within the epithelium covering circumvallate papillae in the tongue (Fig. 5F).

\section{The UA009 Ag Is Expressed by Adipocytes and Steroidogenic Cells}

With the exception of platelets, the distribution of the UA009 Ag had striking similarities to the distribution of CD36 in humans (Febbraio et al, 2001) and CD36/FAT in rats (Abumrad et al, 1993; Fukuwatari et al, 1997; Guthmann et al, 1999; van Nieuwenhoven et al, 1995). We examined, therefore, the expression of the UA009 $\mathrm{Ag}$ in adipose tissue. The antigen was detected on adipocytes in both white fat (Fig. 6A) and brown fat (Fig. 6B). Because the CD36 gene family member SR-B1 is expressed in steroidogenic cells, we examined endocrine cells in the adrenal, testis, and ovary (Figs. 6, $\mathrm{C}$ to E). In addition to vascular sinusoids, mAb UA009 stained parenchymal cells in the inner zona fasciculata and zona reticularis of the adrenal cortex
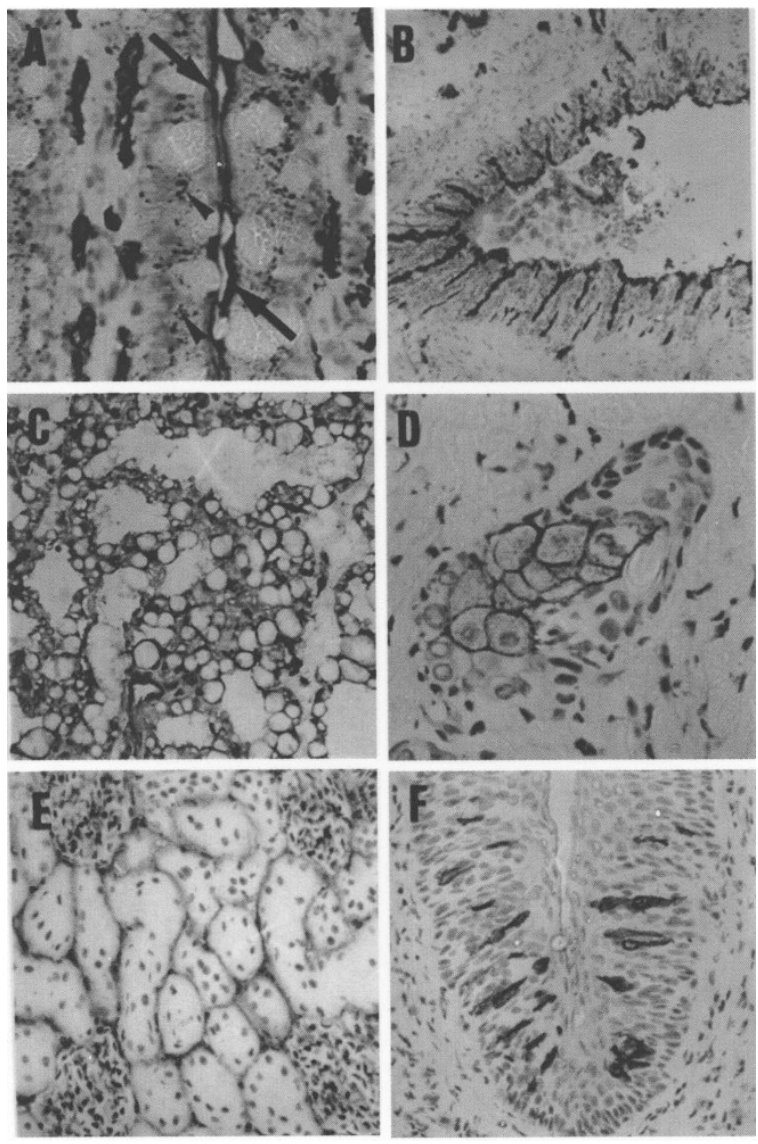

Figure 5.

Staining of epithelia by mAb UA009, using the indirect immunoperoxidase technique. A, The brush border (arrows) of mature enterocytes on villi in the jejunum express the UA009 Ag. There is also staining in the supranuclear regions of enterocytes (arrowheads). Capillaries in the lamina propria stain strongly. B, The lumenal ciliated surface of epithelium in a bronchus stains strongly. C, The vacuolated apocrine epithelium in lactating mammary gland expresses the UA009 Ag. D, Surface staining of apocrine epithelium in a sebaceous gland. E, Polarized expression of the UA009 Ag on the abluminal membranes of renal tubules. $F$, Cells in the epithelium of a circumvallate papillus are stained strongly by mAb UA009. Original magnification: $B, \times 41$; $A, C, E$, and $F, \times 82 ; D, \times 165$.

but not cells in either the zona glomerulosa or the medulla. In the testis, there was strong staining of the interstitial Leydig cells, whereas in the ovary there was staining of granulosa cells in follicles at various stages of maturity. Granulosa cells nearest the lumen of the follicle stained most strongly (Fig. 6E).

To verify that the antigen detected by mAb UA009 was not SR-B1, we examined serial sections of the ovary, in which SR-B1 has a characteristic distribution on cells of the corpus luteum and on the thecal cells that surround the follicles (Landschulz et al, 1996). As shown in Figure 7A (rabbit anti-SR-B1) and Figure 7B (rabbit anti-Giardia, negative control), when stained with polyclonal anti-SR-B1 Ab, there is specific staining of thecal cells and of a corpus luteum, whereas the granulosa cells of the follicles are unstained. In contrast, mAb UA009 stained granulosa cells in the follicles (Fig. 7C), whereas only endothelial cells and macrophages were stained in the corpus luteum and 

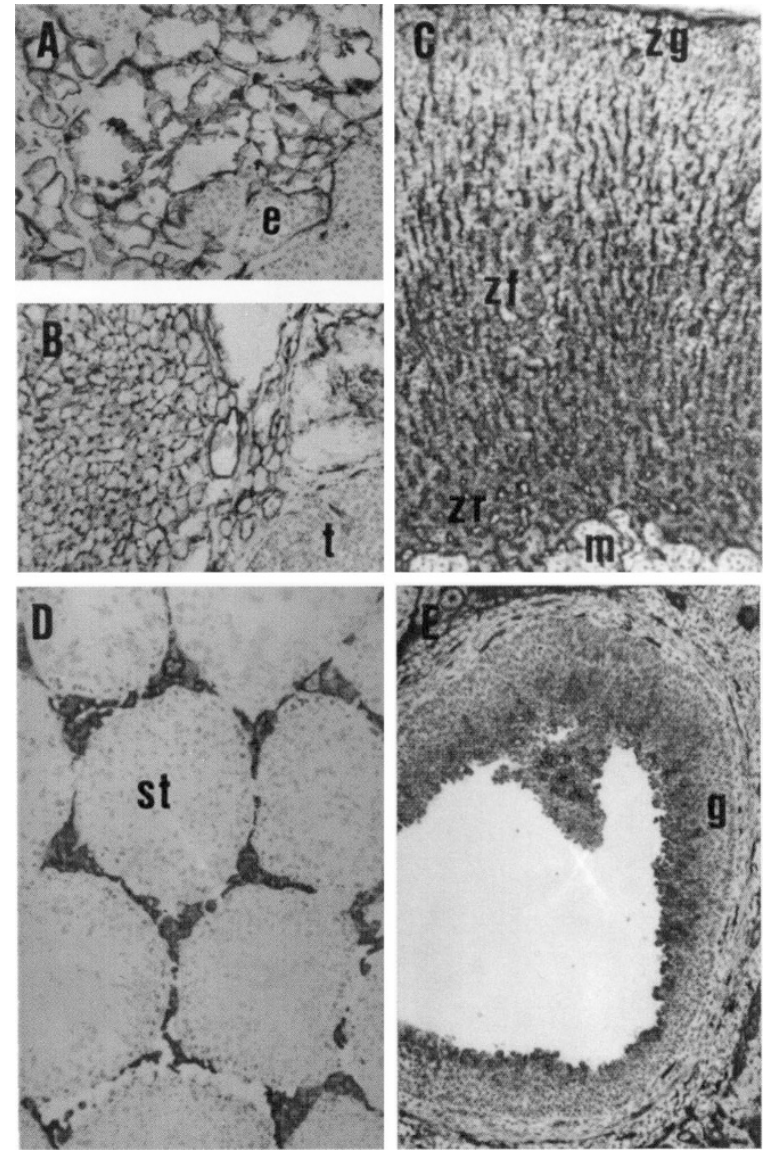

Figure 6.

Expression of the UA009 Ag by adipocytes and steroidogenic cells, detected by the indirect immunoperoxidase technique. A, Adipocytes in white fat are stained by mAb UA009, whereas resting mammary gland epithelium $(e)$ is unstained. B, Brown fat is stained, whereas the attached thyroid gland $(t)$ is unstained. C, Parenchymal cells in the zona reticularis (zr) and zona fasciculata $(z f)$ of the adrenal cortex are stained. Only vascular sinusoids are stained in the medulla $(m)$ and zona glomerulosa $(z g)$. D, Leydig cells in the testis express the UA009 Ag, but the seminiferous tubules $(s t)$ are unstained. E, A mature follicle in the ovary, showing increasing staining of the granulosa cells $(g)$ toward the lumen. Original magnification: $A$ to $E, \times 41$.

there was no staining of the thecal cells. There was no staining with mAb 1B5, the isotype control (Fig. 7D).

\section{Expression of the UAO09 Ag in Liver}

A further distinguishing feature of CD36/FAT is the reported low abundance of Cd36/Fat transcripts and of the protein in the liver in Sprague-Dawley (SD) rats (Abumrad et al, 1993; Pelsers et al, 1999; van Nieuwenhoven et al, 1995). Surprisingly, there was strong staining of hepatocytes in sections of liver from female Dark Agouti (DA) rats. The staining had a centrilobular distribution, the zone of stained cells extending almost to the periphery of the lobule (Fig. 8A). In contrast, in sections of liver from males of the same strain, the antigen was confined to a thin rim of hepatocytes surrounding the central veins of lobules (Fig. 8B). To differentiate staining of parenchymal and sinusoidal cells, hepatocytes were isolated from livers of female and male rats (Figs. 8, C and D). In both cases,
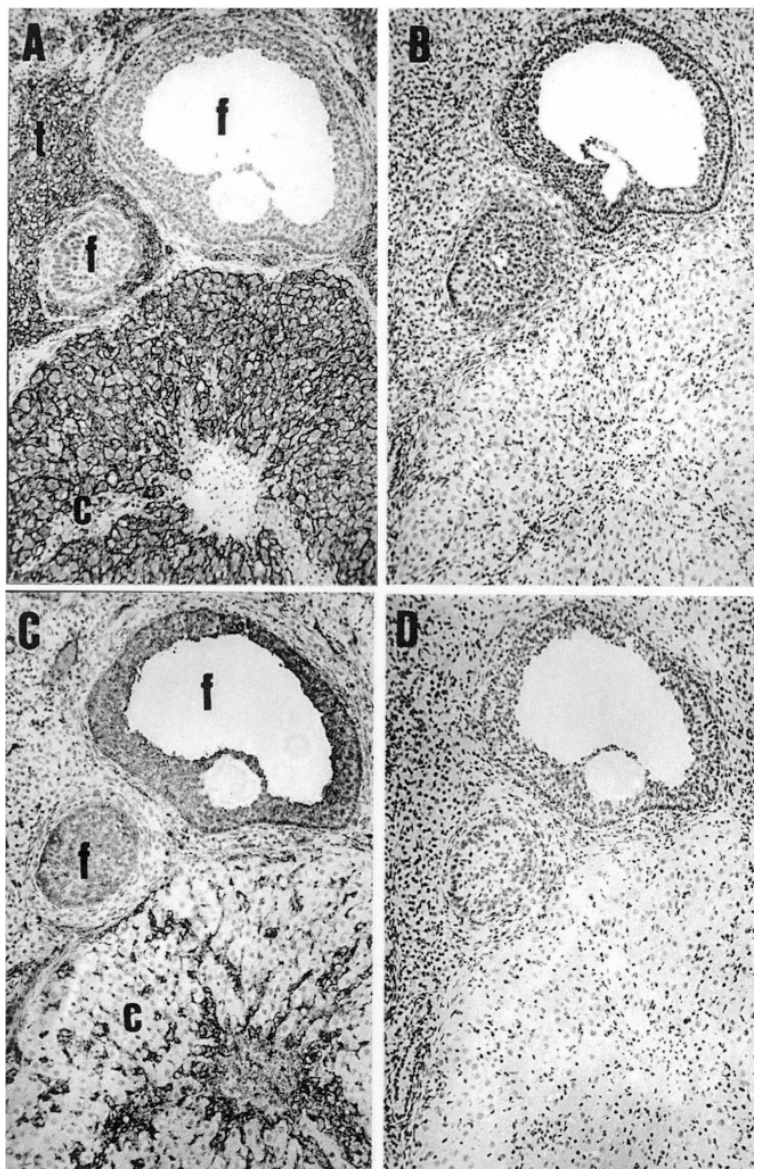

Figure 7.

Comparison of the distribution of SR-B1 and the UA009 Ag in the ovary, using the indirect immunoperoxidase technique. A, Staining of thecal cells $(t)$ surrounding two immature follicles $(f)$ and luteal cells in an adjacent corpus luteum $(c)$ by rabbit anti-SR-B1 polyclonal Ab. B, Absence of staining of ovarian tissue by rabbit anti-Giardia IgG Ab (negative control). C, Staining of granulosa cells of the follicles $(f)$ and of vascular endothelium and macrophages in the adjacent corpus luteum (c) by mAb UA009. Thecal and luteal cells are unstained. D, Ovarian tissue is not stained by mAb $1 \mathrm{~B} 5$ (IgG1 anti-Giardia, negative control). Original magnification: $A$ to $D, \times 41$.

hepatocytes expressed the UA009 Ag, but many fewer were stained by mAb UA009 in preparations from male rats.

In addition to sexual dimorphism, we also observed differences in the level of expression of the UA009 Ag in the liver between female rats of several strains. Importantly, there were no discernible differences in staining by mAb UA009 between female rats of the DA strain and the SD strain, both exhibiting strong staining of most hepatocytes in the lobules (Figs. 8A and 9A). In other strains, exemplified by PVG/c, staining was confined to the centers of lobules (Fig. 9B), whereas in the Brown Norway strain, only the hepatocytes surrounding the central vein expressed the antigen (Fig. 9C). The strains that we have examined can be ranked in order of expression (area of the lobules occupied by stained hepatocytes) as follows: DA (RT1 $\left.{ }^{\text {av}), ~ S D ~(r a n d o m ~ b r e d), ~ W i s t a r ~ F u r t h ~(R T 1 ~}{ }^{\mathrm{u}}\right)>$ PVG/c $\left(R T 1^{\circ}\right)$, F344 $\left(R T 1^{\text {lvi }}\right)>$ Brown Norway $\left(R T 1^{\eta}\right)$. As in the DA rats, the sexual dimorphism in hepatic 
expression of the antigen was observed also in the SD strain (not shown).

\section{Immunoprecipitation of the UA009 Ag from Hepatocyte Lysate and Detection by Western Blot}

Hepatocytes from female rats were chosen as a source of material from which to characterize the UA009 Ag, for comparison with CD36/FAT. A polypeptide of apparent mol wt $85 \mathrm{kDa}$ was immunoprecipitated by mAb UA009 from detergent NP40 lysates of the cells (Fig. 10A). This polypeptide was not present in immunoprecipitates produced by either mAb 1 A29 (anti-intercellular adhesion molecule-1) or mAb 1B5 ( $\operatorname{lgG}_{1}$ isotype control). When examined by Western blot (Fig. 10B), mAb UA009 labeled the 85-kDa band in the immunoprecipitate specifically. In the material immunoprecipitated by mAb $1 \mathrm{~A} 29$, the major band labeled by mAb $1 \mathrm{~A} 29$ had an apparent mol wt of 90 $\mathrm{kDa}$ (consistent with intercellular adhesion molecule1), whereas no immunoreactive material was precipitated or detected by mAb 1B5. mAb UA009 also precipitated a mol wt $85-\mathrm{kDa}$ polypeptide from lysates of surface-biotinylated hepatocytes, detected in Western blot with a streptavidin-biotinylated horseradish peroxidase (HRP) complex (not shown).

\section{Immunopurification of UA009 $\mathrm{Ag}$}

The UA009 Ag was immunopurified from hepatocyte lysate using mAb UA009 conjugated to Sepharose 4B. Approximately $0.5 \mathrm{mg}$ of protein was obtained from the hepatocytes prepared from one liver. When this material was examined by reduced SDS-PAGE, Coomassie blue staining revealed a major band of apparent mol wt $85 \mathrm{kDa}$ (Fig. 10C). This band, but not a fainter band with apparent mol wt $65 \mathrm{kDa}$, was stained by mAb UA009 after Western transfer (Fig. 10D). A polypeptide with similar mol wt was also immunopurified from lysates prepared from peritoneal macrophages and from erythrocytes, which also express the UA009 Ag (not shown).

\section{N-Terminal Amino Acid Sequence of the UA009 Ag Is Similar to CD36/FAT}

After electrophoresis by SDS-PAGE under reducing conditions, the separated proteins from $100 \mu \mathrm{g}$ of immunopurified material were electroblotted to polyvinylidene diflouride membrane and stained with Coomassie blue; a strip containing the $85-\mathrm{kDa}$ band was submitted for $\mathrm{N}$-terminal amino acid analysis. The polypeptide was found to have an unblocked amino terminus, and three runs of analysis yielded a consensus sequence of GXDRNXGLITXAVIG. Comparison with amino acid sequences lodged in GenBank indicated that this sequence was similar to the $\mathrm{N}$-terminus of human, mouse, and bovine CD36 $(80 \%, 80 \%$, and $74 \%$ similarity, respectively) and that there was also similarity $(80 \%$ overall, $100 \%$ at unambiguous residues) to the $\mathrm{N}$-terminus of the polypeptide FAT (Abumrad et al, 1993).

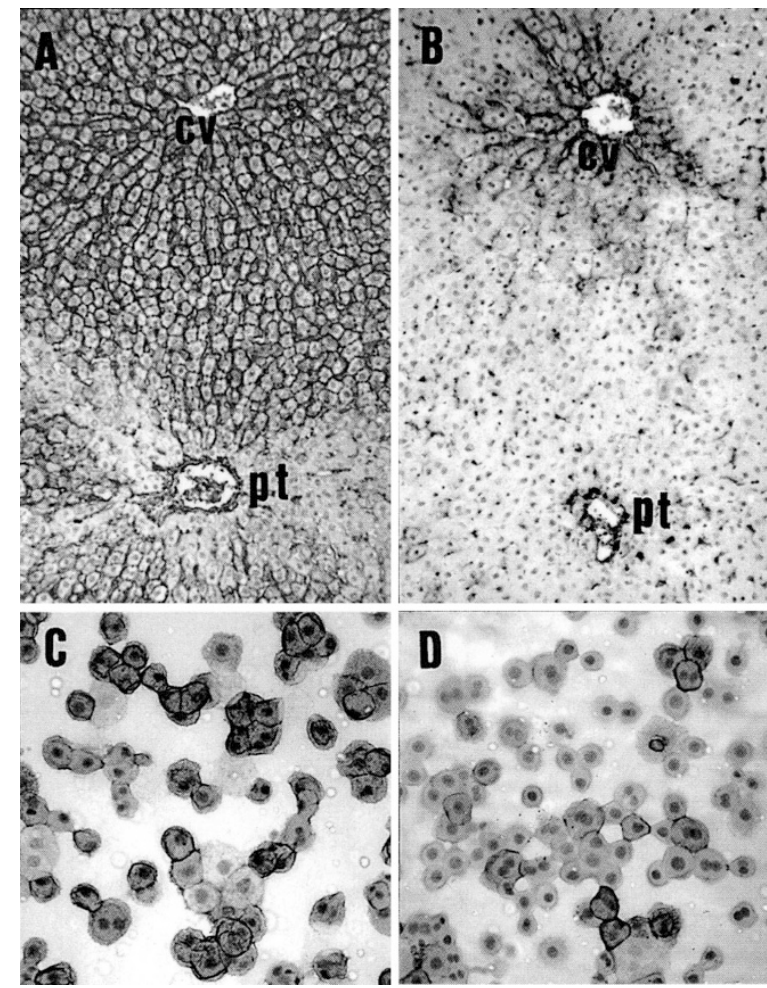

Figure 8.

Gender affects expression of the UA009 Ag in the liver. A, Liver from an adult female DA rat. Hepatocytes are stained by mAb UA009 in a zone extending from the central vein $(c v)$ of a lobule, almost to the portal tract $(p t)$. B, Liver from an adult male DA rat. In comparison with livers from female DA rats, only a thin rim of hepatocytes around the central vein $(C V)$ is stained by $m A b$ UA009. C, Most hepatocytes in suspensions prepared from adult female DA rats are stained by mAb UA009. D, Only a minority of hepatocytes is stained in preparations from adult male rats. Original magnification: $A$ and $B, \times 82 ; C$ and $\mathrm{D}, \times 165$.
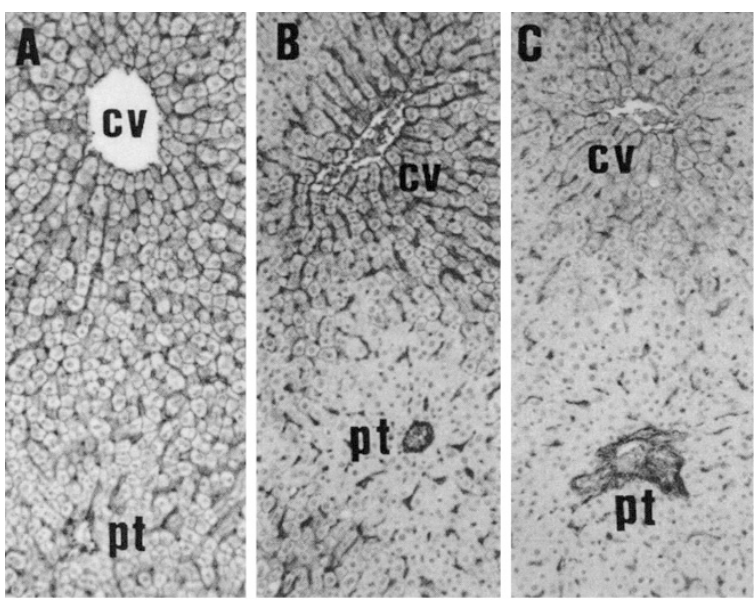

\section{Figure 9.}

Strain affects expression of the UA009 Ag in the liver. A, Most hepatocytes in a liver lobule from a female Sprague-Dawley (SD) rat are stained by $m A b$ UA009. B, mAb UA009 stains hepatocytes in the center of a lobule in liver from a female PVG/c rat. C, In female Brown Norway rats, mAb UA009 stained only the hepatocytes adjacent to the central vein $(c v)$. $p t=$ portal tract. Original magnification: $A$ to $D, \times 82$. 

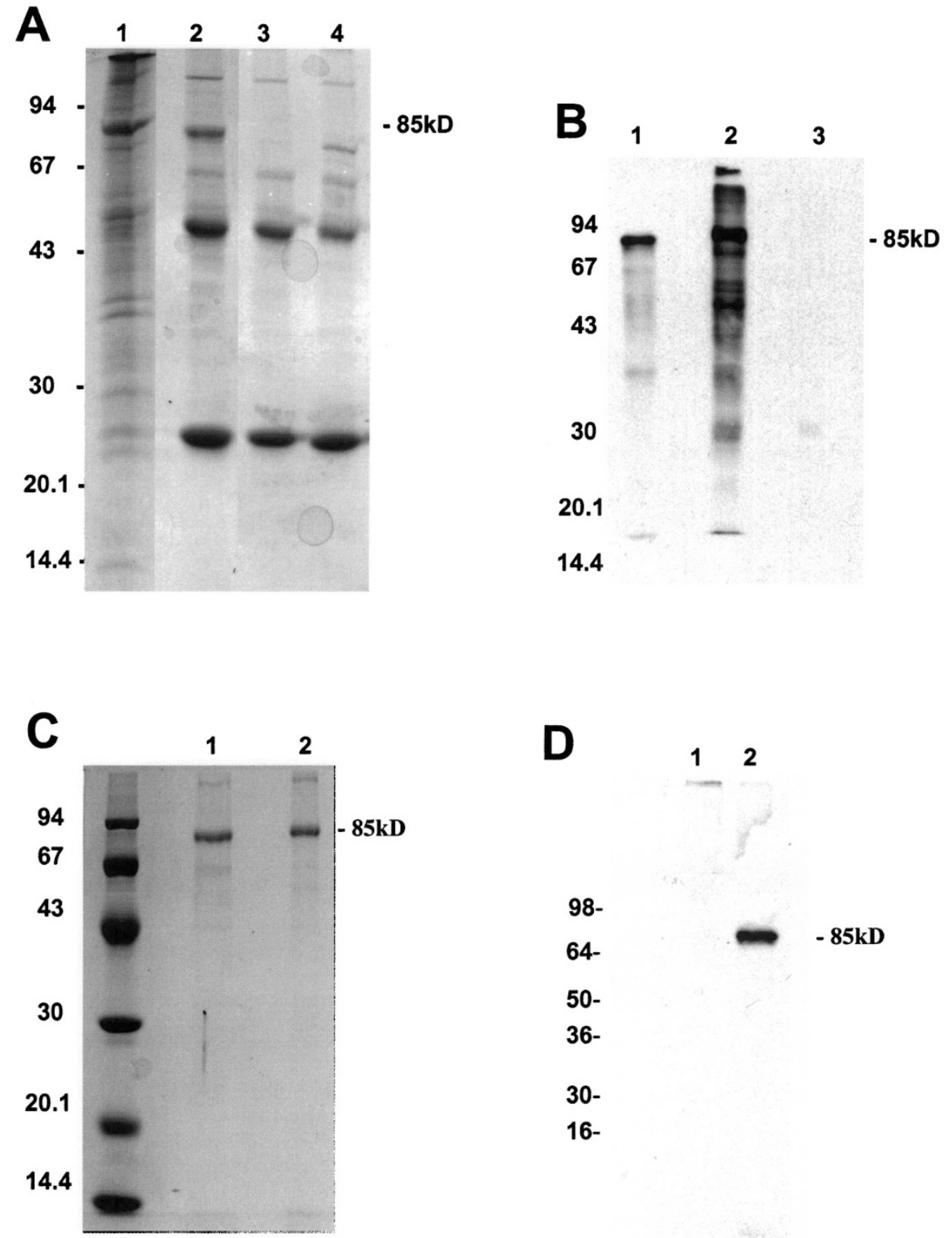

\section{Figure 10.}

The antigen immunoprecipitated ( $A$ and $B$ ) and immunopurified ( $C$ and $D)$ using mAb UA009 was analyzed by SDS-PAGE, and polypeptides were stained with Coomassie (A and C) or identified by Western blot (B and D). A, Lane 1, crude NP40 hepatocyte lysate. Lanes 2 to 4, immunoprecipitates obtained using mAbs UA009, 1A29 (anti-intercellular adhesion molecule-1), and 1B5 (anti-Giardia), respectively. Only mAb UA009 immunoprecipitated a mol wt $85 \mathrm{kDa}$ polypeptide. B, Western blot of immunoprecipitates prepared using mAbs UA009 (Lane 1), 1A29 (Lane 2), and 1B5 (Lane 3), respectively. The 85-kDa polypeptide was detected by mAb UA009 (Lane 1); mAb 1 A29 detected a mol wt approximately $90 \mathrm{kDa}$ polypeptide (Lane 2), whereas mAb 1 B5 did not detect an immunoprecipitate (Lane 3). C, An immunoaffinity (mAb UA009) column purified the mol wt $85 \mathrm{kDa}$ polypeptide to near homogeneity. Lane 1, nonreduced. Lane 2, reduced. D, There is no reaction of mAb 1B5 with the immunopurified polypeptide (Lane 1). Lane 2, mAb UA009 reacted with the immunopurified polypeptide but not with a minor mol wt $65 \mathrm{kDa}$ contaminant.

\section{Amplification of cDNA from Rat Liver and Heart mRNAs by $R T-P C R$}

Abumrad et al (1993) and van Nieuwenhoven et al (1995) did not detect transcripts encoding FAT in Northern blots of RNA prepared from rat liver, although transcripts were detected in RNAs prepared from heart and other tissues. We undertook, therefore, to amplify segments of the gene encoding FAT from rat heart and liver cDNAs by PCR (Fig. 11). Oligonucleotides FP1, FP2, and FP3, complementary to sequences of FAT cDNA (see "Materials and Methods"), all amplified products of the sizes expected from reactions containing FP1 or FP2 in com- bination with RP1 (0.97 kb and $0.63 \mathrm{~kb}$, respectively) or FP3 in combination with RP2 $(0.47 \mathrm{~kb})$ when using either rat liver cDNA, rat heart cDNA, or plasmid pSG5 DNA as templates.

\section{Nucleotide Sequences of the Complete Coding Regions of the cDNAs Amplified from Liver and Heart RNA and Comparison with cDNAs Encoding CD36 and SR-BI}

The above amplification products, plus FP4-RP1 (1.06 $\mathrm{kb})$ and FP3-RP3 (0.68 kb), were purified from bands after agarose gel electrophoresis and subjected to nucleotide sequence analysis. Oligonucleotide prim- 


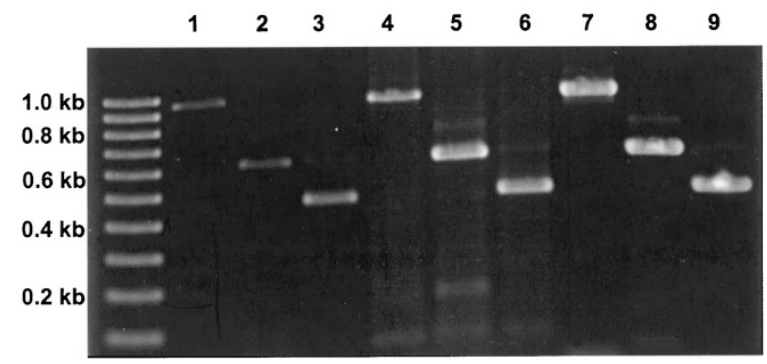

Figure 11.

Agarose gel electrophoresis of products amplified from DA rat heart (Lanes 1 to 3), liver (Lanes 4 to 6), and FAT (Lanes 7 to 9, plasmid pSG5) cDNAs by PCR, using the oligonucleotide primer pairs FP1-RP1 (Lanes 1, 4, and 7), FP2-RP1 (Lanes 2, 5, and 8), and FP3-RP2 (Lanes 3, 6, and 9). Bands of expected sizes $(0.97,0.63$, and $0.47 \mathrm{~kb})$ were obtained using each template.

ers FP4 (5'-uncoded region) and RP3 (3'-uncoded region) span the entire coding region of FAT CDNA, from -18 (including the ATG start codon) to +58 (including the TAA stop codon). The 1492-bp sequence obtained from liver cDNA, containing a 1416-bp open reading frame, has been submitted to GenBank (Access. No. AF113914). The nucleotide sequence obtained from liver cDNA was identical to the sequence of the heart cDNA. Furthermore, the sequences obtained from heart and liver cDNAs were identical with the nucleotide sequence of a cDNA encoding CD36/FAT from Wistar rat pneumocytes (GenBank Access. No. AF072411) and 99.1\% similar to cDNA encoding CD36/FAT from SD rat adipocytes (GenBank Access. No. L19658). The nucleotide sequences predict five conservative (positions 66, 256, 261, 362, and 383) and four nonconservative (positions 85, 214, 257, and 340) amino acid substitutions between the polypeptides in DA and SD strain rats. The level of interstrain nucleotide sequence variation is comparable with that seen between cDNAs encoding CD36 from two human sources (99.9\% similarity) (GenBank Access. Nos. M98398 and S67532) and two bovine sources (98.3\% similarity) (GenBank Access. Nos. D45364 and X91503). In contrast, nucleotide sequences of cDNAs encoding CD36/FAT in Wistar rats were only $48.2 \%$ similar to a cDNA encoding SR-B1 in rats (GenBank Access. No. U76205) and $45.0 \%$ similar to a cDNA encoding SR-B1 in bovines (GenBank Access. No. AF019384). The small differences between the cDNAs encoding CD36/FAT in SD and Wistar rats and the cDNA that we have amplified from DA rat liver seem to reflect polymorphisms in the Cd36/Fat gene.

\section{Absence of the UA009 Ag in SHR/N Rats}

To verify the assignment of the UA009 Ag as CD36/ FAT, we examined SHR rats originating from the $\mathrm{NIH}$ inbred substrain (SHR/N). Animals derived from this inbred line have been shown to be CD36/FAT null (Aitman et al, 1999; Gotoda et al, 1999). We detected no staining by mAbs UA009 or 1B5 (isotype-matched negative control) of either hepatocytes or vascular structures in frozen sections of female SHR/N liver
(Fig. 12, A and B). In contrast (Fig. 12, C and D), both hepatocytes and vascular endothelium were stained in sections of liver from female Wistar Kyoto rats (the strain from which the SHR mutation arose) and in sections from CD36/FAT-replete (Gotoda et al, 1999) female SHR/SP rats (stroke prone substrain of SHR, inbred independently from the SHR/N substrain).

\section{Reactivity of mAb UA009 with COS-7 Cells Transfected with FAT cDNA}

Finally, it was important to examine whether mAb UA009 reacts with the polypeptide encoded by Cd36/ Fat cDNA. When examined by indirect immunofluorescence, mAb UA009 did not bind significantly with untransfected COS-7 cells (not shown). However, after transfection with plasmid pSG5, approximately $17 \%$ of the cells bound mAb UA009 when assessed by flow cytometry (not shown) and they exhibited distinct membrane fluorescence by microscopy (Fig. 13, $A$ and $B)$.
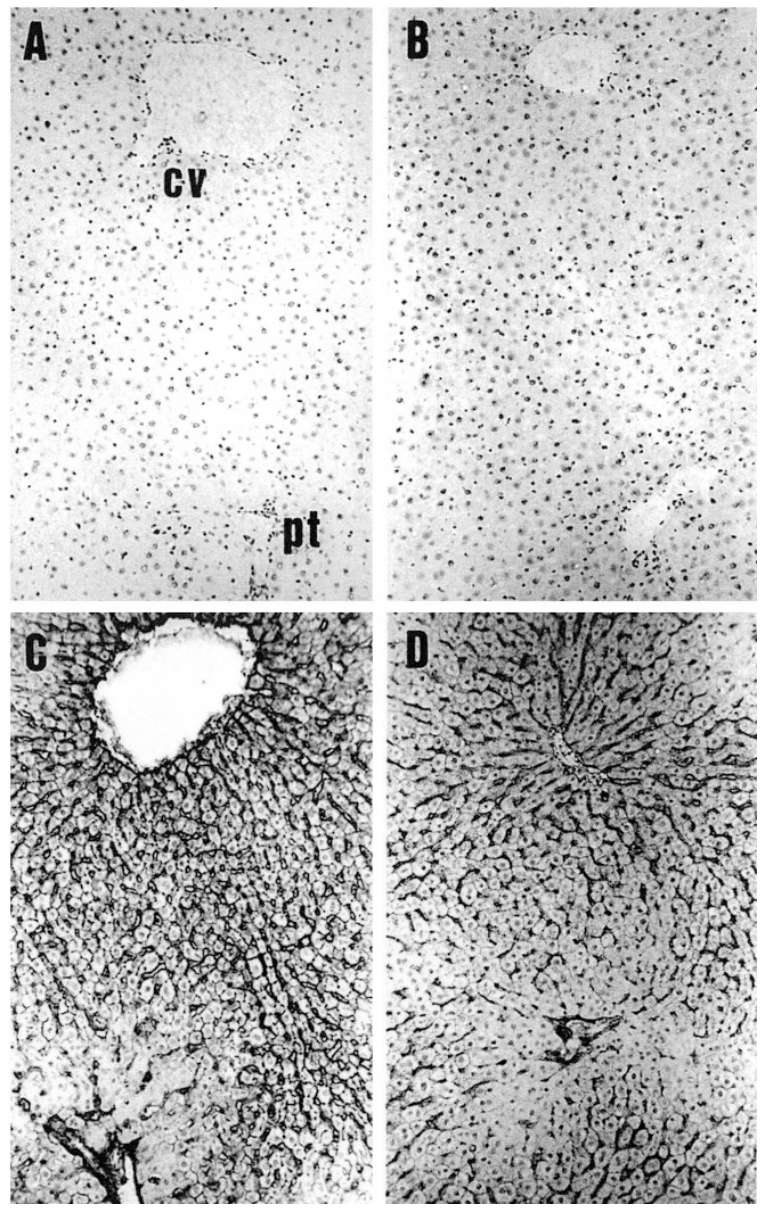

Figure 12.

Detection of the UA009 Ag in frozen sections of liver from female SHR/N, SHR/SP, and Wistar Kyoto (WKY) strain rats, using the indirect immunoperoxidase technique. Each photomicrograph shows a central vein $(c V)$ and a portal tract $(p t)$. A, Liver from a SHR/N rat, stained with isotype-matched control mAb 1B5. B, Liver from a SHR/N rat, mAb UA009. C, Liver from a WKY rat, mAb UA009. D, Liver from a SHR/SP rat, mAb UA009. Original magnification: $\times 41$. 

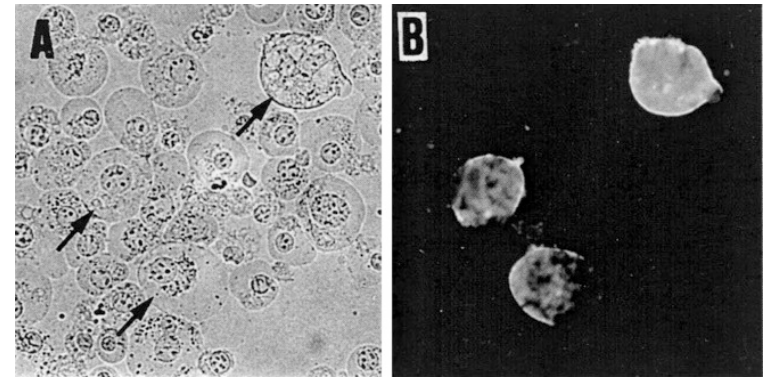

Figure 13.

Detection of CD36/FAT expressed by COS-7 cells transfected with expression plasmid pSG5, using mAb UA009 (primary Ab) and FITC-conjugated F(ab') sheep anti-mouse Ig to label viable transfectants. After fixation, the cells were viewed by phase microscopy (A) and by fluorescence microscopy (B). Arrows, cells exhibiting immunofluorescence. Original magnification: $\times 165$.

\section{Discussion}

The discovery of a FAT and its identification as the ortholog of CD36 (Abumrad et al, 1993) has added to the considerable importance of the rat as a subject for experimental studies in lipid metabolism. It is significant, therefore, that most studies on this translocase have involved either transfection of Cd36/Fat cDNA into cell lines in vitro (Ibrahimi et al, 1996) or the detection of gene activity in vivo. Transcriptional activity of $C d 36 / F a t$ has been detected in tissues such as heart, red muscle, gut, kidney, and spleen by Northern analysis of RNA (Abumrad et al, 1993; Bonen et al, 1998; van Nieuwenhoven et al, 1995), and protein has been detected by ELISA and Western blot in muscle (Bonen et al, 1998; Pelsers et al, 1999). However, the precise nature of the cells within these tissues that express the gene has not been demonstrated directly. This is of some importance, because in other species CD36 has a broad distribution on nonparenchymal cells, some of which are either residents or transients in many tissues. These include adipocytes, vascular endothelium, erythrocytes, macrophages, and platelets (Febbraio et al, 2001).

In the case of the rat, there is a paucity of immunohistochemical information on the distribution of CD36/ FAT. It was of interest, therefore, that mAb UA009 recognized an antigen with a tissue distribution that is similar in most respects to CD36 in other species. Furthermore, the $A b$ immunoprecipitated a polypeptide with apparent mol wt $85 \mathrm{kDa}$ from detergent lysates of hepatocytes, peritoneal macrophages, and erythrocytes, and it stained the surface membranes of COS-7 cells transfected with Cd36/Fat cDNA in plasmid pSG5 (Ibrahimi et al, 1996). It seems, therefore, that mAb UA009 recognizes either CD36/FAT or a CD36/FAT-like molecule. Importantly, the immunohistochemical comparison of the distribution of the UA009 Ag and SR-B1 in the ovary indicated that mAb UA009 does not react with this other CD36 gene family member.

The sequence of the $\mathrm{N}$-terminus of the polypeptide immunopurified from hepatocytes had $80 \%, 80 \%$, and $74 \%$ similarity with mouse, human, and bovine CD36 orthologs, respectively. Furthermore, this sequence
(GXDRNXGLITXAVIG) was identical at all unambiguous residues with those in the corresponding segment of CD36/FAT, while sharing only two residues with the predicted amino acid sequence (SSRARWVALGLGVLG) of the aligned rat ortholog of SR-BI (Ibrahimi et al, 1996; Johnson et al, 1998). The other member of the CD36 gene family identified in rats is the lysosomal protein, LIMPII (Vega et al, 1991). This mol wt $74 \mathrm{kDa}$ lysosomal polypeptide is unlikely to be confused with the UA009 Ag.

The identification of the UA009 Ag as CD36/FAT was strengthened further by the use of RT-PCR to amplify a cDNA with the size expected for Cd36/Fat from RNA prepared from either liver or heart. The nucleotide sequences of the cDNAs amplified from both sources were identical. Furthermore, both contained coding regions that were identical in length and $99 \%$ similar in nucleotide sequence to the open reading frame reported for CDNA encoding CD36/FAT in SD rats (Abumrad et al, 1993). This level of similarity is also found between Fat (SD) and Fat (Wistar) and between the nucleotide sequences encoding CD36 in individual humans or bovines. The open reading frame encodes a polypeptide containing 472 amino acids, which distinguishes it from SR-B1, which is a polypeptide of 509 amino acids (Calvo and Vega, 1993; Johnson et al, 1998).

It seems, therefore, that the gene expressed in the liver in DA strain rats is an allele of the Cd36/Fat locus. Four of the 14 nucleotide differences between Cd36/ Fat in DA and SD rats do not produce amino acid substitutions, six result in five conservative substitutions (residues 66, 256, 261, 362, and 283), and four introduce nonconservative substitutions (residues 85 , 214,257 , and 340). In DA rats, the amino acids at these polymorphic positions are all identical to those reported in Wistar rats (Guthmann et al, 1999) and in humans (Oquendo et al, 1989) and differ from those in mice (Endemann et al, 1993) and bovines (Berglund et al, 1996) by conservative substitutions at one residue (261) and two residues (256 and 261), respectively. Conclusive identification of the UA009 Ag as CD36/ FAT comes from the absence of the UA009 Ag in SHR/N rats, which are reported to be CD36/FAT null (Aitman et al, 1999). Henceforth, the antigen will be referred to as CD36/FAT.

In many respects, the distribution of CD36/FAT in rat tissues correlates with the known functions of the molecule. In particular, it is expressed by a number of cell types that are known to take up fatty acids for transport, energy metabolism, storage, or secretion. Specifically, CD36/FAT is expressed at the brush borders of enterocytes, by cells in sebaceous glands and in lactating mammary glands, and by adipocytes in both white and brown fat. Furthermore, it is expressed by cardiac and red striated skeletal muscle, both of which have a high dependence on fatty acids for energy metabolism (van der Vusse et al, 1992, 1998). In contrast white muscle, which relies mainly on glucose for energy metabolism, expresses minimal CD36/FAT. Others have shown that red muscle contains higher levels of transcripts encoding CD36/FAT 
(Northern analysis) and more CD36/FAT protein (ELISA and Western blot) than white muscle (Bonen et al, 1998; Pelsers et al, 1999), but the results presented here indicate that it is the red muscle fibers themselves that express CD36/FAT. Expression of CD36/ FAT by cells of the renal tubules, which also use fatty acids for energy metabolism (Kurokawa et al, 1985), is consistent with a report that $\mathrm{Cd} 36 /$ Fat transcripts can be detected in this organ (Abumrad et al, 1993).

Expression of CD36/FAT has been described in the lung, and Cd36/Fat transcripts have been detected in circumvallate papillae. In pulmonary alveolar epithelium (Guthmann et al, 1999), CD36/FAT has been shown to mediate uptake of palmitic acid by type II pneumocytes, which use it for synthesis of surfactant. We find that mAb UA009 stains both alveolar epithelium and the lumenal surface of ciliated respiratory epithelium at all levels in the trachea and bronchial tree. The latter observation raises the possibility that ciliated respiratory epithelium may use CD36/FAT to salvage fatty acids and/or cholesterol from surfactant. Fatty acids scavenged in this way could help to support the energy requirements of cilia activity, and a similar situation could exist in the ciliated epithelium of the oviducts. Others have demonstrated that gustatory cells in circumvallate papillae express Cd36/Fat mRNA (Fukuwatari et al, 1997), and our observations show that the cells express CD36/FAT protein.

CD36/FAT has attracted most attention as a scavenger receptor, which may facilitate uptake of denatured low-density lipoprotein (Endemann et al, 1993; Febbraio et al, 2001) and apoptotic cells (Puente Navazo et al, 1996; Sambrano and Steinberg, 1995). Expression of CD36/FAT by monocytes and macrophages is consistent with these functions and with expression of CD36 in other species. In particular, expression of CD36/FAT by macrophages in the medulla of lymph nodes and by reticular elements in the spleen would be consistent with a role in the removal of effete or apoptotic cells from the lymphatic and blood circulations, respectively.

In vascular endothelium, CD36/FAT may be involved with transport of fatty acids from plasma (van der Vusse et al, 1998). However, the molecule also has adhesion functions that could be significant. As a receptor for thrombospondin and collagen, it may be important in the adherence of activated platelets to vessel walls (Febbraio et al, 2001). We found that CD36/FAT was expressed by microvascular endothelium in most tissues other than the central nervous system, but we did not detect the molecule on either megakaryocytes or platelets. This suggests that there is a species difference between rats and other species (human, bovine, and mouse) in the expression of CD36/FAT by platelets. In the rat, expression of CD36/ FAT by red cells and monocytes could allow these cells to interact with activated platelets and complement the absence of CD36/FAT molecule on platelets. In this way, platelets could coaggregate with red cells and/or monocytes, assisting formation of thrombus on damaged endothelium. The inference by Pelsers et al (1999) that rat platelets, but not vascular endothelium, express CD36/FAT is not correct. However, we cannot exclude the possibility that mAb UA009 detects a posttranslational variant of CD36/FAT that is not expressed by platelets. It is noteworthy that another mAb, OX43, has been shown previously to stain in a pattern similar to mAb UA009 and to recognize a mol wt $\sim 90 \mathrm{kDa}$ surface antigen (Robinson et al, 1986). We have found that this $A b$ stains tissues in a pattern indistinguishable from mAb UA009, that it binds to immunopurified UA009 Ag (not shown), and that it reacts with Cd36/Fat-transfected COS cells (X Zhang and $G$ Mayrhofer, unpublished data). mAb OX43 is often used as a marker in rats for endothelial cells and macrophages, and it has been used recently to differentiate these cell types from hepatocytes in collagenase digests of liver (Sigal et al, 1999). Our observation that mAbs UA009 and OX43 (not shown) both stain hepatocytes makes either of them a poor choice for this purpose.

The observation that CD36/FAT is expressed at high levels in the liver requires special comment. Three reports, two examining mRNA transcripts and one examining CD36/FAT protein in the liver of rats of the SD strain, concluded that the molecule is expressed at only low levels in the liver (Abumrad et al, 1993; Pelsers et al, 1999; van Nieuwenhoven et al, 1995). This has led to a widely accepted inference that CD36/FAT is not expressed by hepatocytes in rats or in other species, despite at least one report in humans to the contrary (Maeno et al, 1994). The reported absence of CD36/FAT in rat liver has been influential in diverting attention away from roles that the molecule might play in hepatic handling of fatty acids and cholesterol (Febbraio et al, 2001). We have shown that the level of expression of CD36/FAT by hepatocytes is dependent on genetic background. However, the differences between our results and those of others are not a result of strain differences because we found that CD36/FAT is expressed in the liver at similar levels in female rats of the SD and DA strains. In contrast, there is a large difference between adult males and female rats of either strain, with much more extensive expression in the liver of female rats. These observations suggest that previous studies on CD36/FAT in $\mathrm{SD}$ rats have been conducted in males exclusively, although only Pelsers et al (1999) recorded gender. We have found that gonadal steroids regulate hepatic expression of CD36/FAT (RL Fitzsimmons, LG Cleland, and G Mayrhofer, unpublished data).

The overlap in expression of CD36/FAT and SR-B1 in the liver and the steroidogenic tissues may have fundamental significance. In the case of steroidogenic cells, fatty acids could provide a source of acetyl CoA for de novo cholesterol synthesis. Although CD36/FAT could act exclusively as a long chain fatty acid transporter in these tissues, it is also possible that the molecule might be involved in uptake of cholesterol from HDL. Recent evidence indicates that CD36 and SR-BI have similar binding affinities for HDL (Connelly et al, 1999; Gu et al, 1998), although SR-BI mediates cholesterol uptake from HDL into cells several times more effectively than CD36 (Connelly et al, 1999). 
Significantly, mice bearing a homozygous null mutation in the gene encoding CD36 (Febbraio et al, 1999) exhibit a serum lipid phenotype similar to that observed in SR-BI null mice (Rigotti et al, 1997). The raised serum cholesterol in these mice is puzzling, because the effect of the null mutation appears large in comparison with the modest effect that CD36 expression has on cholesteryl ester uptake by cells in tissue culture (Connelly et al, 1999).

In this context, we draw attention to two important gender-related dimorphisms in lipid metabolism. The first is the long-recognized difference in long chain fatty acid uptake and utilization in the livers of male and female rats (Ockner et al, 1979). There is no explanation of this difference that is wholly satisfactory, either in terms of the known plasma membrane fatty acid binding protein (FABPpm) or cytosolic fatty acid binding protein (Luxon et al, 1998; Sorrentino et al, 1992). The second is the difference between men and premenopausal women with respect to both blood cholesterol levels and the incidence of cholesterol-associated diseases (Anderson et al, 1987; Barker et al, 1979; Simons, 1986).

These differences are thought to result either directly or indirectly from effects of ovarian steroid hormones. Our observation that gender affects the level of CD36/FAT expression in the liver may, therefore, be significant on the one hand because of the function of this molecule as a FAT (Abumrad et al, 1993; Ibrahimi et al, 1996) and on the other hand because of the important role the liver plays in reverse cholesterol transport and the excretion of cholesterol in bile (Krieger,1998). Others have shown that pharmacologic doses of estrogen lower hepatic expression of SR-BI in mice. Paradoxically, this treatment lowers plasma cholesterol (Landschulz et al, 1996). In contrast, the higher expression of CD36/FAT in the liver in female rats seems to correlate well with the observed effects of gender and sex steroids on blood cholesterol levels. Nevertheless, the effects of blocking SR-BI in vitro by the use of Abs (Temel et al, 1997), of making null mutations in the gene encoding the protein (Rigotti et al, 1997), or of overexpressing SR-BI in the liver in vivo (Kozarsky et al, 1997) indicate that SR-BI plays an important role in cholesterol homeostasis.

We offer the following hypotheses to explain this paradox and the gender difference in hepatic handling of fatty acids. The gene encoding CD36/FAT, which contains a glucocorticoid response element (Armesilla and Vega, 1994), may be responsive to sex steroids, thus explaining our observations on the effects of sex and of gonadectomy on hepatic expression of CD36. With respect to uptake of fatty acids by the liver, we suggest that the level at which CD36/FAT is expressed by hepatocytes may be a sufficient explanation for the gender difference reported in rats. However, Sorrentino et al (1992) have suggested that the affinity of FABPpm for long chain fatty acids may be gender regulated. This is difficult to envision in molecular terms unless CD36/FAT and FABPpm interact cooperatively, thus increasing the apparent affinity of FAB-
Ppm and increasing the efficiency of fatty acid transport by hepatocytes in female rats.

In the case of cholesterol, we suggest that constitutive expression of SR-B1 by hepatocytes maintains serum cholesterol at the levels observed in male rats. We suggest further that CD36/FAT plays an ancillary role to $\mathrm{SR}-\mathrm{BI}$ in selective cholesterol uptake by the liver, that it may be in part responsible for the effects of sex on blood cholesterol levels, and that, ultimately, CD36/FAT expression in the liver could prove to be a major determinant of the gender effect on susceptibility to cholesterol-related disease. CD36/FAT could accomplish this role, either because it is expressed in women at levels several-fold higher than SR-BI and/or because it interacts synergistically with SR-BI in cholesterol-rich areas of the cell membrane (Babitt et al, 1997). Because both molecules bind HDL with high affinity (Connelly et al, 1999; Gu et al, 1998), it seems possible that CD36/FAT could act primarily to capture HDL, while SR-BI acts as a common conduit to shuttle cholesteryl ester to the cell membrane. The latter mechanism would reconcile the apparent primacy of SR-BI over CD36/FAT in cholesterol uptake. If CD36/ FAT were upstream of SR-BI in the handling on HDL cholesterol, SR-BI deficiency would compromise selective cholesterol uptake via either receptor. Conversely, a limit on the uptake of cholesteryl ester by SR-BI would affect interpretation of experiments in which CD36/FAT is overexpressed in the liver (de Villiers et al, 2001). If the strain and sex variations that we have noted in expression of CD36/FAT in the liver in rats can be extended to humans, they could indicate potential risk factors for cholesterol-related diseases. It is vital that CD36 expression be investigated in human liver, using a large sample that includes both men and women. Similar investigations are important in mice, because genetic manipulation in this species is being used increasingly to examine cholesterol and lipid metabolism.

\section{Materials and Methods}

\section{Animals}

Specific pathogen-free inbred DA rats were obtained from the Animal Resource Center of the Institute for Medical and Veterinary Science, Adelaide. Random bred SD rats were from the Central Animal House of the University of Adelaide. All other strains were obtained from the Animal Resource Center at Murdoch University, Western Australia. Unless stated otherwise, the rats were females. Approval was obtained from the Animal Ethics Committees of The University of Adelaide and the Institute of Medical and Veterinary Science, Adelaide.

\section{Abs and Affinity Matrices}

The hybridoma secreting mAb UA009 (IgG1, kappa light chain) was obtained from a fusion between X63 mouse myeloma cells and spleen cells obtained from a Balb/C mouse that had been immunized with lymph node cells from normal DA rats. The Ab was affinity 
purified from ascites fluid using a Protein $G$ column (Protein G Sepharose 4 Fast Flow; Pharmacia LKB, Uppsala, Sweden) and biotinylated by direct conjugation with biotin (EZ-Link Sulfo-NHS-Biotin; Pierce, Rockford, Illinois). The mAbs 1A29 (anti-intercellular adhesion molecule-1, CD54), WT.5 (anti-Mac-1), and OX43 (uncharacterized) have been described elsewhere (Robinson et al, 1986; Tamatani and Miyasaka, 1990; Tamatani et al, 1991). An IgG1 mouse antiGiardia mAb (IB5) was used as an isotype-matched negative control $\mathrm{Ab}$ (G Mayrhofer, unpublished data). Three milligrams of purified mAb UA009 was coupled to $0.3 \mathrm{mg}$ of $\mathrm{CNBr}$-activated Sepharose 4B (Pharmacia). Affinity-purified mAbs 1A29 and 1B5 were also coupled to Sepharose 4B, to be used as positive and negative controls, respectively. The secondary $A b$ used in indirect immunohistochemistry was an HRP conjugate of $F\left(a b^{\prime}\right)_{2}$ sheep anti-mouse IgG (Amersham, Buckinghamshire, United Kingdom). Polyclonal rabbit anti-mouse SR-B1 (raised against a peptide fragment of the intracellular carboxy-terminus and cross-reactive with rat SR-B1) was obtained from Novus Biochemicals (Littleton) and HRP-conjugated donkey anti-rabbit IgG was obtained from Rockland (Gilbertsville, Pennsylvania). Affinity-purified rabbit anti-Giardia variable surface antigen, used as negative control polyclonal IgG, was kindly provided by $\mathrm{Dr}$. Peter Ey (Department of Molecular Biosciences, University of Adelaide). FITC-conjugated $F\left(a b^{\prime}\right)_{2}$ sheep anti-mouse IgG (PharMingen, San Diego, California) was used as the secondary $A b$ in indirect immunofluorescence labeling for flow cytometry.

\section{Tissue Samples and Immunohistochemistry}

Tissue samples were removed under either halothanenitrous oxide or ether anesthesia. Tissues sampled were as follows: liver, small intestine (including Peyer's patch), large intestine, pancreas, lung, kidney, skin, tongue, heart, skeletal muscle (diaphragm, sternomastoid, soleus, gastrocnemius), adrenal, testis, ovary, uterus, Fallopian tube, seminal vesicle, prostate, bladder, cerebrum, spleen, lymph nodes, thymus, aorta, vena cava, and bone marrow (Hermans and Opstelten, 1991). Tissue blocks were embedded in OCT medium (Tissue-Tek; Sakura Finetek) and snap-frozen in isopentane chilled with liquid nitrogen. Frozen sections $(5 \mu \mathrm{m})$ were air-dried and fixed in 95\% ethanol before staining by the indirect immunoperoxidase technique (Spargo et al, 1996). Briefly, rehydrated sections were incubated with primary $\mathrm{mAb}$ for 1 hour, rinsed with PBS, and incubated for a further 1 hour with a 1/20 dilution of HRP-conjugated antimouse IgG (in the case of polyclonal anti-SR-B1, the primary $\mathrm{Ab}$ was used at a dilution of $1 / 300$ and the donkey anti-rabbit IgG-HRP conjugate was used at a dilution of 1/50). After washing, the sections were incubated for 10 minutes in $0.05 \mathrm{M}$ Tris buffer $(\mathrm{pH} 7.6)$ containing $0.02 \%$ hydrogen peroxide and $5 \mathrm{mg} / \mathrm{ml}$ diaminobenzidine (Sigma, St. Louis, Missouri), rinsed, and counterstained with Gill's hematoxylin. The stained sections were photographed using a blue filter and Kodak Technical Pan film (Eastman Kodak, Rochester, New York).

\section{Preparation of Isolated Hepatocytes and Cardiac Myocytes}

Hepatocytes were prepared by perfusion of the liver with collagenase as described elsewhere (Rofe et al, 1980). Cardiac myocytes were isolated and supplied by Dr. E. J. McMurchie, CSIRO Division of Human Nutrition, Adelaide (Abeywardena et al, 1984). The washed cells were smeared on slides, air-dried, fixed with $95 \%$ ethanol, and stained by the indirect immunoperoxidase technique.

\section{Preparation of Cells for Flow Cytometry}

Platelet-rich plasma and red cells were obtained by centrifugation of citrated blood at $100 \times g$ for 10 minutes. The pellet provided red cells, and the platelets were recovered from the supernatant by centrifugation at $1500 \times g$ for 10 minutes. Platelets were activated by incubation with $40 \mu \mathrm{g} / \mathrm{ml}$ thrombin (Sigma) for 15 minutes. To make platelets permeable, they were fixed for 15 minutes with $1 \%$ paraformaldehyde, treated with $0.1 \%$ Saponin (Sigma), and remained in Saponin for all subsequent steps. Macrophages were obtained either by lavage of the peritoneal cavity or by lavage of the lungs via a tracheal cannula. The cells were recovered by centrifugation at $100 \times g$ for 10 minutes. Cells were labeled for flow cytometric analysis by incubation in primary $\mathrm{Ab}$ (hybridoma culture supernatant, containing $10 \%$ normal rat serum plus $0.01 \mathrm{M}$ sodium azide) for 1 hour on ice. After three washes in $\mathrm{PBS} / 2 \% \mathrm{FCS} / 0.01 \mathrm{~m}$ sodium azide at $4^{\circ} \mathrm{C}$, the cells were incubated with FITC-conjugated sheep anti-mouse IgG for 1 hour; after a further three washes, they were fixed in PBS containing 1\% formaldehyde. Flow cytometry was performed using a FACScan (Becton Dickinson, San Jose, California) equipped with CellQuest software (versions 2.1 and 3.1f).

\section{Preparation of Hepatocyte Lysate}

Hepatocytes were prepared as described above (Rofe et al, 1980). After washing, they were recovered by centrifugation (100 $\times g$ for 5 minutes). In some cases, hepatocytes were surface biotinylated using the method of Cole et al (1987). The hepatocytes from one liver were then lysed in $30 \mathrm{ml}$ of TSE buffer $(50 \mathrm{~mm}$ Tris-Hcl, $150 \mathrm{~mm} \mathrm{NaCl}, 1 \mathrm{~mm}$ EDTA) containing 1\% NP40 detergent (BDH, Poole, United Kingdom) in the presence of protease inhibitors (Cole et al, 1987) at final concentrations of $40 \mu \mathrm{g} / \mathrm{ml}$. After centrifugation at $500 \times g$ for 10 minutes, the postnuclear supernatant was clarified by centrifugation at $60,000 \mathrm{rpm}(150,000$ $\times g$ ) for 1 hour at $4^{\circ} \mathrm{C}$.

\section{Immunoprecipitation of Cell-Surface Proteins}

The lysate from $10^{7}$ hepatocytes was incubated on a rotator for 2 hours with Sepharose 4B beads conju- 
gated to purified mAbs. The beads were then washed five times with $0.5 \%$ NP40/TSE and twice with $0.05 \%$ NP40/TSE, and boiled with $15 \mu$ l of loading buffer for 5 minutes. Samples were then analyzed by electrophoresis on SDS polyacrylamide gels (12\%). Protein bands were detected by staining with Coomassie blue, and replicate tracks were electroblotted to nitrocellulose (Protran; Schleicher and Schuell, Dassel, Germany). For Western blot, the target protein was detected by incubating the nitrocellulose with biotinylated mAbs, followed by the streptavidin-biotinylated HRP complex (Amersham). Bound complex was demonstrated by incubation with chemiluminescence reagent (Renaissance; NEN, Boston, Massachusetts) and exposure to x-ray film (BioMax; Kodak). The target proteins in lysates from biotinylated hepatocytes were detected by incubation with the streptavidinbiotinylated HRP complex (as above).

\section{Affinity Purification of mAb UA009-Reactive Proteins and Determination of N-Terminal Amino Acid Sequence}

Proteins reactive with mAb UA009 were captured by rotation of $100 \mathrm{ml}$ of clarified hepatocyte lysate overnight at $4^{\circ} \mathrm{C}$ with $10 \mathrm{ml}$ of Ab-coupled Sepharose 4B beads. After washing five times with $0.5 \%$ NP40/TSE, the beads were loaded into a column and washed further. The UA009 Ag was eluted with $0.5 \mathrm{M}$ propionic acid in $0.05 \%$ NP40/TSE; the eluate was neutralized with $1 \mathrm{M}$ Tris base, dialyzed against a 1/10 dilution of PBS containing $0.05 \%$ NP40, concentrated by Centriprep (Amicon, Beverly, Massachusetts), and analyzed by SDS-PAGE, using a $12 \%$ gel. The separated proteins were electroblotted to a polyvinylidene difluoride membrane (Bio-Rad, Hercules, California) using $10 \mathrm{~mm}$ 3-cyclohexylamino-1-propanesulfonic acid buffer (Sigma). The membrane was stained with $0.025 \%$ Coomassie bright blue, and a major band with estimated mol wt $85 \mathrm{kDa}$ was excised and submitted to Dr. Verne Bowles (Centre for Animal Biotechnology, University of Melbourne) for $\mathrm{N}$-terminal amino acid sequencing.

\section{RT-PCR Amplification of CDNA}

Poly $\mathrm{A}^{+}$RNA was prepared from rat liver and heart, essentially as described by Gonda et al (1982). Briefly, tissue was homogenized for 30 seconds at 20,000 rpm after adding proteinase K (BDH Merck, Auburn, Australia) $(200 \mu \mathrm{g} / \mathrm{ml})$ and SDS (0.5\%) and then incubated with oligo dT-cellulose (Boehringer Mannheim, Mannheim, Germany). The poly $A^{+}$RNA was eluted from the column and stored in ethanol at $-20^{\circ} \mathrm{C}$. First-strand cDNA was synthesized, using a First Strand cDNA Premix kit (Pharmacia Biotech Asia, Hong Kong) and oligo dT primer to reverse transcribe $250 \mathrm{ng}$ of the poly $\mathrm{A}^{+}$RNA (Zannettino et al, 1996). PCR was performed using the cDNA as template, together with the following primers (Macromolecular Resources, Fort Collins). Forward primers were FP1, 5' ACTGGAGCCGTTATTGGTGC; FP2, 5' CCTTCACTGTCTGTTGGCAC; FP3, 5' TGTTCTTCCAGCCAACGC-
CT; and FP4, 5' TGTACCTGTGAGTTGGCAAG. Reverse primers were RP1, 5' TGCACGTTGCCAATGTCCAGC; RP2, 5' CCAACACCAAGTAAGACCATCTC; and RP3, 5' TAAGAGAGAGAGCGCGCAC. Forward primers (FP1, FP2, and FP3) and reverse primers (RP1 and RP2) were designed using Primers software to amplify segments corresponding to residues 104-123, 443-462, 952-971, 1073-1092, and 1427-1449, respectively, in the published nucleotide sequence of the FAT cDNA (GenBank Access. No. L19658). The additional oligonucleotide primers (FP4 and RP3, complementary to residues 13-32 and 1633-1651, respectively) were designed to produce an amplicon including segments of the $5^{\prime}$ and $3^{\prime}$ noncoding sequences of the FAT cDNA.

The PCR was performed by adding $5 \mu$ of $10 \times$ dNTP (2 mm) (Pharmacia Biotech Asia), $5 \mu$ l of $10 \times$ buffer (Boehringer Mannheim, Indianapolis, Indiana), and the primers (final concentration $5 \mu \mathrm{M}$ ) to $1 \mu \mathrm{l}$ of cDNA preparation. The volume was adjusted to $29 \mu \mathrm{l}$, and after addition of $1 \mu \mathrm{l}(0.25 \mathrm{U} / \mu \mathrm{l})$ of Tth DNA polymerase (Boehringer Mannheim, Indianapolis, Indiana), the reaction mixture was subjected to 30 thermal cycles $\left(30\right.$ seconds at $95^{\circ} \mathrm{C}, 30$ seconds at $62^{\circ} \mathrm{C}, 2$ minutes at $72^{\circ} \mathrm{C}$ ). The PCR products were then separated by electrophoresis on $1 \%$ agarose gel, the major band was excised, and the DNA was purified using a JETsorb DNA purification kit (Genomed). For sequencing, $8 \mu$ l of Dye Terminator Ready Reaction Mix (Applied Biosystems, Foster City, California), $5 \mu \mathrm{l}$ of primer, and $4 \mu \mathrm{l}(30 \mathrm{ng} / \mu \mathrm{l})$ of PCR product were adjusted to a volume of $20 \mu \mathrm{l}$ and subjected to 25 thermal cycles (30 seconds at $96^{\circ} \mathrm{C}, 15$ seconds at $50^{\circ} \mathrm{C}, 4$ minutes at $60^{\circ} \mathrm{C}$ ). The product was then sequenced using an Applied Biosystems 373 automated sequence analyzer. The sequencing data was analyzed by DNAsis and PROsis after accessing the databases of GenBank and the European Molecular Biology Laboratory for similar sequences. The sequences from different biologic sources were aligned using Clustal-W software.

\section{Transient Transfection of COS-7 Cells}

Recombinant plasmid pSG5, containing a 1.4-kb insert of cDNA encoding FAT, was provided by Drs. N. A. Abumrad and A. Ibrahimi (State University of New York). Ten micrograms of the plasmid DNA was added to $10^{7}$ COS-7 cells in electroporation buffer (20 mм HEPES, $137 \mathrm{~mm} \mathrm{NaCl}, 5 \mathrm{~mm} \mathrm{KCl,} 7 \mathrm{~mm} \mathrm{Na} \mathrm{HPO}_{4}$, $6 \mathrm{~mm}$ glucose, $0.1 \mathrm{~mm} \beta$-mercaptoethanol). The cells were then transferred to a 0.4-cm cuvette (Bio-Rad) and electroporated using a BioRad Genepulser. The transfected cells were then plated out in a $75-\mathrm{cm}^{2}$ flask in RPMI with 10\% FCS. After 72 hours, the expression of FAT by the COS-7 cells was detected by indirect immunofluorescence. The cells were labeled with mAb UA009 and then incubated with $\mathrm{F}\left(\mathrm{ab} \mathrm{b}^{\prime}\right)_{2}$ sheep anti-mouse $\mathrm{Ig}$, before fixation with $1 \%$ paraformaldehyde. 


\section{Acknowledgements}

The authors are grateful to Ms. Jocelyn Darby for her helpful advice, Dr. Leonie Ashman for generous access to the facilities in her laboratory, and Drs. Allan Rofe and Peter Coyle for provision of isolated hepatocytes.

\section{References}

Abbadia Z, Vericel E, Mathevet P, Bertin N, Panaye G, and Frappart $L$ (1997). Fatty acid composition and CD36 expression in breast adipose tissue of premenopausal and postmenopausal women. Anticancer Res 17:1217-1222.

Abeywardena MY, McMurchie EJ, Russell GR, Sawyer WH, and Charnock JS (1984). Response of rat heart membranes and associated ion-transporting ATPases to dietary lipid. Biochem Biophys Acta 776:48-59.

Abumrad NA, el Maghrabi MR, Amri EZ, Lopez E, and Grimaldi PA (1993). Cloning of a rat adipocyte membrane protein implicated in binding or transport of long-chain fatty acids that is induced during preadipocyte differentiation. J Biol Chem 268:17665-17668.

Acton S, Rigotti A, Landschulz KT, Xu S, Hobbs $\mathrm{HH}$, and Krieger M (1996). Identification of scavenger receptor SR-BI as a high density lipoprotein receptor. Science 271:518-520.

Acton SL, Scherer PE, Lodish HF, and Krieger M (1994). Expression cloning of SR-BI, a CD36-related class B scavenger receptor. J Biol Chem 269:21003-21009.

Aitman TJ, Glazier AM, Wallace CA, Cooper LD, Norsworthy PJ, Wahid FN, Al-Majali KM, Trembling PM, Mann CJ, Shoulders CC, Graf D, St Lezin E, Kurtz TW, Kren V, Pravenec M, Ibrahimi A, Abumrad NA, Stanton LW, and Scott $J$ (1999). Identification of Cd36 (Fat) as an insulin-resistance gene causing defective fatty acid and glucose metabolism in hypertensive rats. Nat Genet 21:76-83.

Anderson KM, Wilson PW, Garrison RJ, and Castelli WP (1987). Longitudinal and secular trends in lipoprotein cholesterol measurements in a general population sample. The Framingham Offspring Study. Atherosclerosis 68:59-66.

Armesilla AL and Vega MA (1994). Structural organization of the gene for human CD36 glycoprotein. J Biol Chem 269: 18985-18991.

Babitt J, Trigatti B, Rigotti A, Smart EJ, Anderson RG, Xu S, and Krieger M (1997). Murine SR-BI, a high density lipoprotein receptor that mediates selective lipid uptake, is $\mathrm{N}$-glycosylated and fatty acylated and colocalizes with plasma membrane caveolae. J Biol Chem 272:13242-13249.

Barker DJ, Gardner MJ, Power C, and Hutt MS (1979). Prevalence of gall stones at necropsy in nine British towns: A collaborative study. Br Med J 2:1389-1392.

Berglund L, Petersen TE, and Rasmussen JT (1996). Structural characterization of bovine CD36 from the milk fat globule membrane. Biochim Biophys Acta 1309:63-68.

Bonen A, Luiken JJ, Liu S, Dyck DJ, Kiens B, Kristiansen S, Turcotte LP, Van Der Vusse GJ, and Glatz JF (1998). Palmitate transport and fatty acid transporters in red and white muscles. Am J Physiol 275:E471-E478.

Calvo D, Gomez-Coronado D, Lasuncion MA, and Vega MA (1997). CLA-1 is an $85-k D$ plasma membrane glycoprotein that acts as a high-affinity receptor for both native (HDL, LDL, and VLDL) and modified (OxLDL and AcLDL) lipoproteins. Arterioscler Thromb Vasc Biol 17:2341-2349.

Calvo D, Gomez-Coronado D, Suarez Y, Lasuncion MA, and Vega MA (1998). Human CD36 is a high affinity receptor for the native lipoproteins HDL, LDL, and VLDL. J Lipid Res 39:777-788.

Calvo D and Vega MA (1993). Identification, primary structure, and distribution of CLA-1, a novel member of the CD36/LIMPII gene family. J Biol Chem 268:18929-18935.

Cao G, Garcia CK, Wyne KL, Schultz RA, Parker KL, and Hobbs HH (1997). Structure and localization of the human gene encoding SR-BI/CLA-1: Evidence for transcriptional control by steroidogenic factor 1 . J Biol Chem 272:3306833076.

Cole SR, Ashman LK, and Ey PL (1987). Biotinylation: An alternative to radioiodination for the identification of cell surface antigens in immunoprecipitates. Mol Immunol 24: 699-705.

Connelly MA, Klein SM, Azhar S, Abumrad NA, and Williams DL (1999). Comparison of class B scavenger receptors, CD36 and scavenger receptor BI (SR-BI), shows that both receptors mediate high density lipoprotein-cholesteryl ester selective uptake but SR-BI exhibits a unique enhancement of cholesteryl ester uptake. J Biol Chem 274:41-47.

de Villiers WJ, Cai L, Webb NR, de Beer MC, van Der Westhuyzen DR, and de Beer FC (2001). CD36 does not play a direct role in HDL or LDL metabolism. J Lipid Res 42:12311238.

Edelman P, Vinci G, Villeval JL, Vainchenker W, Henri A, Miglierina R, Rouger P, Reviron J, Breton-Gorius J, Sureau C, and Edelman $L$ (1986). A monoclonal antibody against an erythrocyte ontogenic antigen identifies fetal and adult erythroid progenitors. Blood 67:56-63.

Endemann G, Stanton LW, Madden KS, Bryant CM, White RT, and Protter AA (1993). CD36 is a receptor for oxidized low density lipoprotein. J Biol Chem 268:11811-11816.

Febbraio M, Abumrad NA, Hajjar DP, Sharma K, Cheng W, Pearce SF, and Silverstein RL (1999). A null mutation in murine CD36 reveals an important role in fatty acid and lipoprotein metabolism. J Biol Chem 274:19055-19062.

Febbraio M, Hajjar DP, and Silverstein RL (2001). CD36: A class $B$ scavenger receptor involved in angiogenesis, atherosclerosis, inflammation, and lipid metabolism. J Clin Invest 108:785-791.

Fukuwatari T, Kawada T, Tsuruta M, Hiraoka T, Iwanaga T, Sugimoto E, and Fushiki T (1997). Expression of the putative membrane fatty acid transporter (FAT) in taste buds of the circumvallate papillae in rats. FEBS Lett 414:461-464.

Gonda TJ, Sheiness DK, and Bishop JM (1982). Transcripts from the cellular homologs of retroviral oncogenes: Distribution among chicken tissues. Mol Cell Biol 2:617-624.

Gotoda T, Lizuka Y, Kato N, Osuga J, Bihoreau MT, Murakami $\mathrm{T}$, Yamori $\mathrm{Y}$, Shimano $\mathrm{H}$, Ishibashi $\mathrm{S}$, and Yamada $\mathrm{N}$ (1999). Absence of Cd36 mutation in the original spontaneously hypertensive rats with insulin resistance. Nat Genet 22:226-228.

Greenwalt DE and Mather IH (1985). Characterization of an apically derived epithelial membrane glycoprotein from bovine milk, which is expressed in capillary endothelia in diverse tissues. J Cell Biol 100:397-408. 
Greenwalt DE, Watt KWK, Hasler T, Howard RJ, and Patel S (1990). Structural, functional, and antigenic differences between bovine heart endothelial CD36 and human platelet CD36. J Biol Chem 265:16296-16299.

Gu X, Trigatti B, Xu S, Acton S, Babitt J, and Krieger M (1998). The efficient cellular uptake of high density lipoprotein lipids via scavenger receptor class B type I requires not only receptor-mediated surface binding but also receptor-specific lipid transfer mediated by its extracellular domain. J Biol Chem 273:26338-26348.

Guthmann F, Haupt R, Looman AC, Spener F, and Rustow B (1999). Fatty acid translocase/CD36 mediates the uptake of palmitate by type II pneumocytes. Am J Physiol 277:L191L196.

Harmon CM, Luce P, Beth AH, and Abumrad NA (1991). Labeling of adipocyte membranes by sulfo-N-succinimidyl derivatives of long-chain fatty acids: Inhibition of fatty acid transport. J Membr Biol 121:261-268.

Hermans MH and Opstelten D (1991). In situ visualization of hemopoietic cell subsets and stromal elements in rat and mouse bone marrow by immunostaining of frozen sections. J Histochem Cytochem 39:1627-1634.

Ibrahimi A, Sfeir Z, Magharaie H, Amri EZ, Grimaldi P, and Abumrad NA (1996). Expression of the CD36 homolog (FAT) in fibroblast cells: Effects on fatty acid transport. Proc Natl Acad Sci USA 93:2646-2651.

Johnson MS, Svensson PA, Helou K, Billig H, Levan G, Carlsson LM, and Carlsson B (1998). Characterization and chromosomal localization of rat scavenger receptor class $B$ type I, a high density lipoprotein receptor with a putative leucine zipper domain and peroxisomal targeting sequence. Endocrinology 139:72-80.

Knowles DM, Tolidjian B, Marboe C, D'Agati V, Grimes M, and Chess $L$ (1984). Monoclonal anti-human monocyte antibodies OKM1 and OKM5 possess distinctive tissue distributions including differential reactivity with vascular endothelium. J Immunol 132:2170-2173.

Kozarsky KF, Donahee MH, Rigotti A, Iqbal S, Edelman ER, and Krieger M (1997). Overexpression of the HDL receptor SR-BI alters plasma HDL and bile cholesterol levels. Nature 387:414-417.

Krieger M (1998). The "best" of cholesterols, the "worst" of cholesterols: A tale of two receptors. Proc Natl Acad Sci USA 95:4077-4080.

Kurokawa K, Nagami GT, and Yamaguchi DT (1985). Transport and substrate metabolism of the kidney. In: Kinne RKH, editor. Renal biochemistry: Cells, membranes, molecules. Amsterdam: Elsevier, 175-223.

Landschulz KT, Pathak RK, Rigotti A, Krieger M, and Hobbs $\mathrm{HH}$ (1996). Regulation of scavenger receptor, class B, type I, a high density lipoprotein receptor, in liver and steroidogenic tissues of the rat. J Clin Invest 98:984-995.

Luxon BA, Holly DC, Milliano MT, and Weisiger RA (1998). Sex differences in multiple steps in hepatic transport of palmitate support a balanced uptake mechanism. Am J Physiol (Gastrointest Liver Physiol) 274:G52-G61.

Maeno Y, Fujioka H, Hollingdale MR, Ockenhouse CF, Nakazawa S, and Aikawa M (1994). Ultrastructural localization of CD36 in human hepatic sinusoidal lining cells, hepatocytes, human hepatoma (HepG2-A16) cells, and C32 amelanotic melanoma cells. Exp Parasitol 79:383-390.
McGregor JL, Catimel B, Parmentier S, Clezardin P, Dechavanne M, and Leung LLK (1989). Rapid purification and partial characterization of human platelet glycoprotein Illb: Interaction with thrombospondin and its role in platelet aggregation. J Biol Chem 264:501-506.

Murao K, Terpstra V, Green SR, Kondratenko N, Steinberg D, and Quehenberger O (1997). Characterization of CLA-1, a human homologue of rodent scavenger receptor $\mathrm{BI}$, as a receptor for high density lipoprotein and apoptotic thymocytes. J Biol Chem 272:17551-17557.

Ockner RK, Burnett DA, Lysenko N, and Manning JA (1979). Sex differences in long chain fatty acid utilization and fatty acid binding protein concentration in rat liver. $\mathrm{J}$ Clin Invest 64:172-181.

Okumura T and Jamieson GA (1976). Platelet glycocalicin. I. Orientation of glycoproteins of the human platelet surface. J Biol Chem 251:5944-5949.

Oquendo P, Hundt E, Lawler J, and Seed B (1989). CD36 directly mediates cytoadherence of Plasmodium falciparum parasitized erythrocytes. Cell 58:95-101.

Pelsers MM, Lutgerink JT, Nieuwenhoven FA, Tandon NN, van der Vusse GJ, Arends JW, Hoogenboom HR, and Glatz JF (1999). A sensitive immunoassay for rat fatty acid translocase (CD36) using phage antibodies selected on cell transfectants: Abundant presence of fatty acid translocase/ CD36 in cardiac and red skeletal muscle and up-regulation in diabetes. Biochem J 337:407-414.

Puente Navazo MD, Daviet L, Savill J, Leung LLK, and McGregor JL (1996). Identification of a domain (155-183) on CD36 implicated in the phagocytosis of apoptotic neutrophils. J Biol Chem 271:15381-15383.

Rigotti A, Acton SL, and Krieger M (1995). The class B scavenger receptors SR-BI and CD36 are receptors for anionic phospholipids. J Biol Chem 270:16221-16224.

Rigotti A, Trigatti BL, Penman M, Rayburn H, Herz J, and Krieger M (1997). A targeted mutation in the murine gene encoding the high density lipoprotein (HDL) receptor scavenger receptor class B type I reveals its key role in HDL metabolism. Proc Natl Acad Sci USA 94:12610-12615.

Robinson AP, White TM, and Mason DW (1986). MRC OX-43: A monoclonal antibody which reacts with all vascular endothelium in the rat except that of brain capillaries. Immunology $57: 231-237$

Rofe AM, James HM, Bais R, Edwards JB, and Conyers RA (1980). The production of (14C) oxalate during the metabolism of (14C) carbohydrates in isolated rat hepatocytes. Aust J Exp Biol Med Sci 58:103-116.

Sambrano GR and Steinberg D (1995). Recognition of oxidatively damaged and apoptotic cells by an oxidized low density lipoprotein receptor on mouse peritoneal macrophages: Role of membrane phosphatidylserine. Proc Natl Acad Sci USA 92:1396-1400.

Sigal SH, Rajvanshi P, Gorla GR, Sokhi RP, Saxena R, Gebhard DR, Reid LM, and Gupta S (1999). Partial hepatectomy-induced polyploidy attenuates hepatocyte replication and activates cell aging events. Am J Physiol 276: G1260-G1272.

Simons LA (1986). Interrelations of lipids and lipoproteins with coronary artery disease mortality in 19 countries. Am J Cardiol 57:5G-10G. 
Sorrentino D, Zhou SL, Kokkotou E, and Berk PD (1992). Sex differences in hepatic fatty acid uptake reflect a greater affinity of the transport system in females. Am J Physiol 263:G380-G385.

Spargo LD, Hawkes JS, Cleland LG, and Mayrhofer G (1996). Recruitment of lymphoblasts derived from peripheral and intestinal lymph to synovium and other tissues in normal rats and rats with adjuvant arthritis. J Immunol 157:5198-5207.

Tamatani T and Miyasaka M (1990). Identification of monoclonal antibodies reactive with the rat homolog of ICAM-1, and evidence for a differential involvement of ICAM-1 in the adherence of resting versus activated lymphocytes to high endothelial cells. Int Immunol 2:165-171.

Tamatani T, Kotani M, and Miyasaka M (1991). Characterization of the rat leukocyte integrin, CD11/CD18, by the use of LFA-1 subunit-specific monoclonal antibodies. Eur J Immunol 21:627-633.

Tandon NN, Lipsky RH, Burgess WH, and Jamieson GA (1989). Isolation and characterization of platelet glycoprotein IV (CD36). J Biol Chem 264:7570-7375.

Temel RE, Trigatti B, DeMattos RB, Azhar S, Krieger M, and Williams DL (1997). Scavenger receptor class B, type I (SR-BI) is the major route for the delivery of high density lipoprotein cholesterol to the steroidogenic pathway in cultured mouse adrenocortical cells. Proc Natl Acad Sci USA 94:13600-13605.

van der Vusse GJ, Glatz JF, Stam HC, and Reneman RS (1992). Fatty acid homeostasis in the normoxic and ischemic heart. Physiol Rev 72:881-940. van der Vusse GJ, Glatz JF, Van Nieuwenhoven FA, Reneman RS, and Bassingthwaighte JB (1998). Transport of long-chain fatty acids across the muscular endothelium. Adv Exp Med Biol 441:181-191.

van Nieuwenhoven FA, Verstijnen CPHJ, Abumrad NA, Willemsen PHM, van Eys GJJM, van der Vusse GJ, and Glatz JFC (1995). Putative membrane fatty acid translocase and cytoplasmic fatty acid-binding protein are co-expressed in rat heart and skeletal muscles. Biochem Biophys Res Commun 207:747-752.

Van Schravendijk MR, Handunnetti SM, Barnwell JW, and Howard RJ (1992). Normal human erythrocytes express CD36, an adhesion molecule on monocytes, platelets, and endothelial cells. Blood 80:2105-2114.

Vega MA, Segui-Real B, Garcia JA, Cales C, Rodriguez F, Vanderkerckhove J, and Sandoval IV (1991). Cloning, sequencing, and expression of a CDNA encoding rat LIMP II, a novel $74-\mathrm{kDa}$ lysosomal membrane protein related to the surface adhesion protein CD36. J Biol Chem 266:1681816824.

Zannettino AC, Rayner JR, Ashman LK, Gonda TJ, and Simmons PJ (1996). A powerful new technique for isolating genes encoding cell surface antigens using retroviral expression cloning. J Immunol 156:611-620. 